\title{
OPTIMUM AMBULANCE LOCATION IN SEMI-RURAL AREAS
}

Richard A. Volz

Highway Safety Research Institute

University of Michigan

Huron Parkway and Baxter Road

Ann Arbor, Michigan 48105 
OPTIMUM AMBULANCE LOCATION IN SEMI-RURAL AREAS

by

Richard A. Volz*

\section{Abstract}

As large medical centers become ever more capable, the existence of well equipped, well staffed, and rapid emergency ambulance service becomes increasingly important. This paper presents a method for determining the optimum location of ambulance stations to minimize the average response time to emergency calls. A new point-to-point driving time model is introduced, and a computer optimization algorithm is used to determine optimum locations. A constraint that the average response time to any point in the service area be less than some specified minimum is also considered. The method is applied to Washtenaw County, Michigan.

*The author is with the Department of Electrical Engineering and the Highway Safety Research Institute, The University of Michigan, Ann Arbor, Michigan. 
OPTIMUM AMBULANCE LOCATION IN SEMI-RURAI ARFAS

By Richard A. Volz

\section{Introduction}

Emergency ambulance service is vital in any community, large or small. The availability of an ambulance, or even a few minutes difference in the time of its arrival, may make the difference between life and death for a patient. It is important, therefore, that adequate service be provided and that the facilities available be utilized so as to derive maximum public benefit from them. To achieve this, three basic subsystems of the emergency ambulance service must be considered; they are communication, transportation, and medical treatment. Fortunately, for most purposes these may be considered separately. In this report the second subsystem, transportation, is studied. In particular, the locations at which a given number of ambulances should be stationed to minimize the response time to a call is determined. By noting the results for varying numbers of ambulances one can determine the benefit to be derived from purchasing additional vehicles. These are important considerations, for in many emergency situations one of the most critical factors is how rapidly aid can arrive.

The technical problems which arise in the determination of ambulance locations are similar to those which occur in conjunction with many service- and business-location studies. Banks have considered location determination for branch offices, reliqious organizations for church sites, governmental agencies for a variety of services, etc. (See [1], [2], and [3] for a few examples.) The list could be very long, since the problem has been considered in many different contexts. In most cases, however, the work was primarily that of analysis. Only recently have people bequn to utilize simulation and optimization techniques. Notable examples of this are the studies on fire station location currently being conducted by the Fels Institute at the University of Pennsylvania, and Dartmouth College, and the investiqations into ambulance location by Savas [4], and by Gordon and Zelin [5]. 
Savas studied the allocation and location of ambulances for a hospital district in New York City. The primary results obtained there were: the number of ambulances should be sufficient to prevent the formation of significant queues, the ambulances should be dispersed throughout the service area, and large service areas with no district restrictions on ambulance travel were most efficient.

The study described in this report differs from that conducted in New York City in several ways. It was conducted for Washtenaw County, a semi-rural area in southeastern lower Michigan (see fig. 1), whose basic characteristics differ from those of a district or section of a large city. The population density is much lower. Consequently, a requirement that there be enough vehicles to prevent significant queues from forming is inadequate. With the smaller total population, the number of ambulances necessary to prevent this is quite sma11. The larger geographical area, on the other hand, poses an additional problem. Enough ambulances must be available to keep the driving time to various points in the county acceptably sma11. In semi-rural Washtenaw County this number is larger than that required to prevent significant queues.

Also, there is a basic difference in approach in this investigation. In the Savas study, the locations of the dispersed ambulances were determined through trial and error by a human operator using Monte Carlo techniques with a relatively straight-forward simulation model. In this effort, a more complex driving time model is used with explicit equations for the average response time, and the ambulance locations are determined by an iterative optimization algorithm. The purpose of the study is twofold: to obtain explicit usable results for Washtenaw County, and to investigate the feasibilities of the model and of the optimization procedures used for semi-rural areas.

This report is organized so the nonmathematically-oriented reader may study it without being encumbered with detailed equations. Chapter 2 discusses the problem formulation and the basic assumptions and approximations made; it also describes the data base used for the study. Chapter 3 presents the results. All of the detailed derivations of the equations are contained in the appendices. 


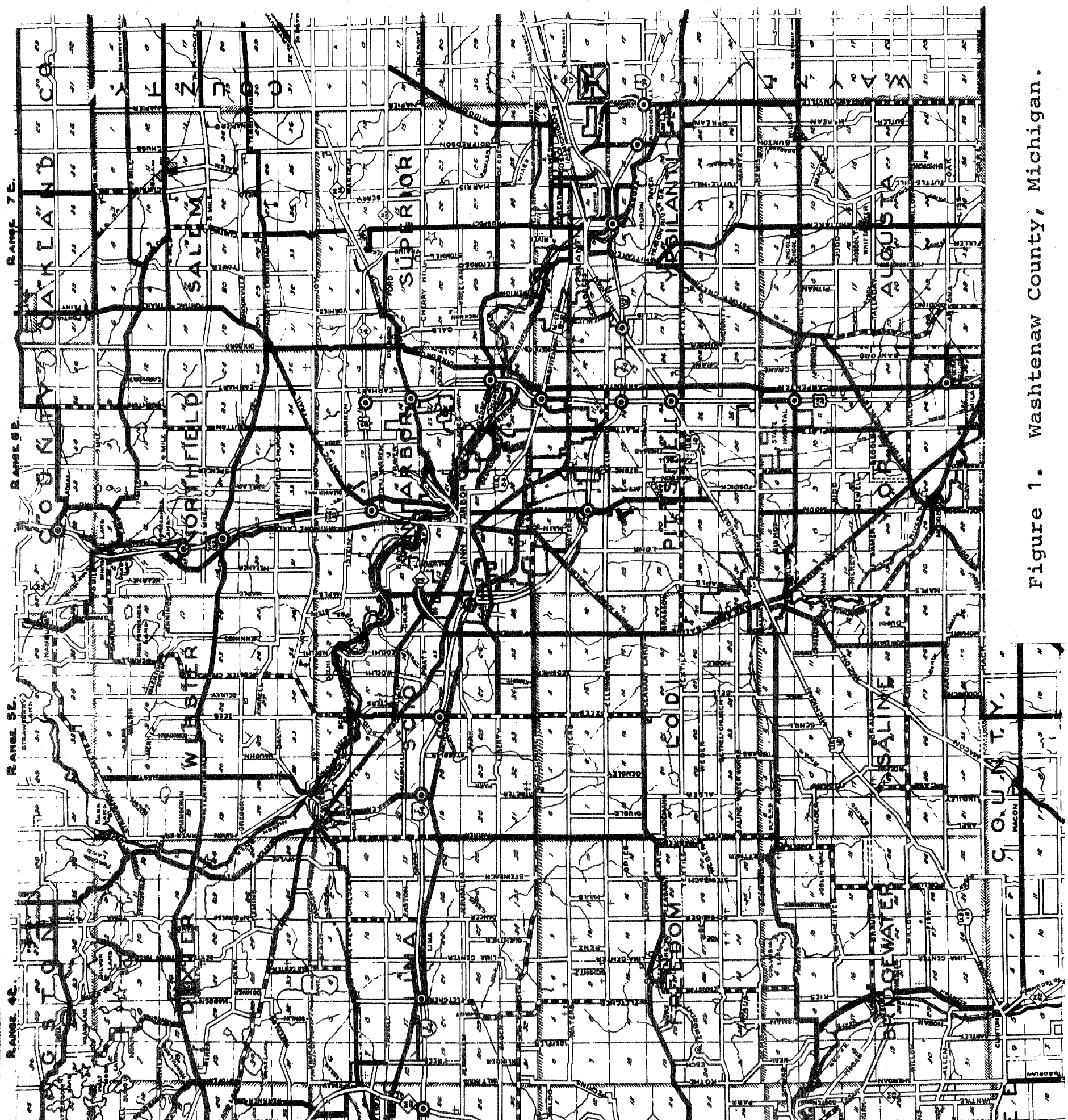

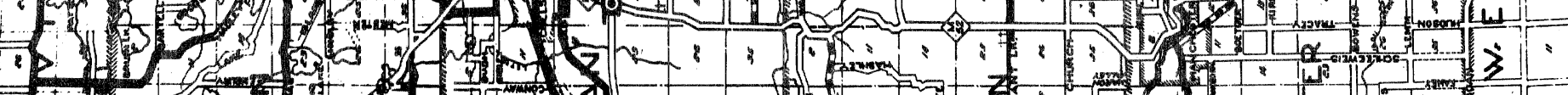
E. (1) 
Problem Statement and Assumptions

One of the important characteristics of an ambulance service is its ability to respond rapidly to emergency calls. There are many important factors which influence this; they include the number of ambulances assigned, the locations at which they are stationed, road conditions, time of day, day of week, etc. Over many of these factors the ambulance service has little or no control, e.g. time of call. Consequently, we examined two factors over which control can be exercized - the number of ambulances and their station locations - and treated all other factors as uncontrolled random inputs. As a means of evaluating the system performance, the response time - defined as the time difference between the receipt of a call requesting ambulance service and the arrival of an ambulance at the scene - is useful. However, it is not only the response to a single call that is important, but the overall performance of the system. Consequently, the average response time with respect to all emergency calls in the county was used. The problem may be stated very simply as follows:

Problem 1. Given that there are $N$ ambulances to provide service to the county, determine the station locations for these ambulances which minimize the expected (or average) value of the response time.

The effect the number of ambulances has on the response time can be determined by solving problem 1 for varying values of $N$.

An expression for the average response time, denoted $\overline{\mathbb{T}}$ ' is developed in Appendix A. Using the driving time model described in Appendix $B$ and the minimization procedures in Appendix $C$, a set of ambulance locations was determined which minimized $\bar{T}_{r}$. In these developments, several simplifying assumptions and approximations were made. Reasonable operating procedure dictates that when a call is received, the nearest (in the sense of driving time) ambulance 
should be dispatched. It was assumed that if $\mathrm{K}$ ambulances are in service, the remaining, $\mathrm{N}-\mathrm{K}$, ambulances are optimally located. That is, we assumed that every time an ambulance goes into service, the remaining vehicles are instantaneously relocated in an optimal manner.* The fact that transition from one station location to another is not instantaneous would be a problem only if a vehicle received a call during a transition. Since the transition time is sma11, the probability of this occurring is also small. Even if this did occur, the ambulance would be on the way to the new station and the time difference in many cases would be small. Consequenty it was felt that this assumption is justified.

A second important consideration is route selection. With known techniques it is not possible to specify the optimum route for the ambulance in a short enough time to allow the solution to problem 1 to be carried out. Therefore it was assumed that the driver would make a reasonable choice of route and that his route would be close to the optimal; it was further assumed that if a reasonable route were picked from the map it would be close (in the sense of driving time) to that actually selected by the driver. It was recognized that this introduces a margin for error. However, more accurate methods do not appear feasible at this time, and it was believed that if care is taken the errors can be held to acceptable limits. The details of the route selection from the map are discussed in Appendix $C$.

To simplify the calculation of $\bar{T}$ " the county, which is 30 miles by 24 miles, was divided into squares one mile on a side. All calls within a one mile square were considered to come from a single representative point within that square and all distances from that square were measured relative to that point. This simplified the arithmetic because each location could then be represented by a pair of integer coordinates. If desired, smaller squares could be used; the procedures would be the same. The only difference is that greater computation time would be required.

* The idea of dynamically relocating the remaining vehicles is reasonable since the existing ambulance service utilizes a relocation scheme. 
To achieve simplification it was assumed that the source of a call and the number of vehicles in service when it is received are statistically independent of all the variables in the system. In a strict sense this need not be true. For example, poor road conditions would lead to a greater number of highway accidents, and thus it would change somewhat the distribution on source of calls. However, the errors should be relatively small, and if desired, the problem could be segmented to achieve an even better approximation. One could solve the problem under different fixed conditions; e.g., 4-6 p.m. on weekdays when traffic is heavier, or times for which roads are covered with snow. For each of these a different solution may be obtained, and for each the assumption is valid. While this segmentation is theoretically possible, neither the data to make many segmented solutions meaningful nor the funds to support the necessary computer work were available. Consequently, no such segmentation was done.

Finally, it was assumed that there is always an ambulance available when a call is received. That is, a user would never need to wait for an ambulance to be released from a previous call. This is reasonable since only twice during a 12 -month period were all of the ambulances in the present service simultaneously in use.

The response time, then, was evaluated under these assumptions and approximations using the procedures described in Appendices $A$ and $B$. Using the method in Appendix $C$, a digital computer solved for the ambulance locations that minimize $\overline{\mathrm{T}}_{\mathrm{r}}$.

Although the average response time is a significant measure of the ambulance system performance, one might also want to specify that no response be longer than some predetermined maximum, $T_{m}$. In an absolute sense this cannot be quaranteed. However, one could include a constraint which would require that the average response time to any point in the county be less than $\mathrm{T}_{\mathrm{m}}$ if at least $r$ ambulances are available at the time a call is received. This latter condition on the number of ambulances available is necessary because if the number were too low there might be no set of locations from which one could reach any point within $\mathrm{T}_{\mathrm{m}}$ minutes. 
Thus, one can state:

Problem 2: Given that there are $\mathrm{N}$ ambulances to provide service to the county and that the average response time to any call is required to be less than $T_{m}$ if at least $r$ ambulances are available at the time the call is received, determine the ambulance station locations which minimize the expected (or average) value of the response time.

This problem will be called the constrained problem and problem 1 will be referred to as the unconstrained problem.

\section{Data}

The data used in this study were made available through the Washtenaw County Health Department and the Superior Ambulance Company. Superior maintains a thorough record on each call received. Among the pertinent information recorded are the location from which an ambulance left, the location to which it went, the time of the call, the time of departure, the time of arrival at the scene, the time the ambulance left the scene, and the time it arrived at the hospital (or other secondary destination). The times are recorded by a radio dispatcher using a time clock whose scale is in minutes.

The information obtained from these data include the density of emergency calls* in the county, an estimate of ambulance speeds on different types of roads, and the probability that a given number of ambulances will be in use when a call is received. Because response time is most important in emergency cases, only those calls were used in the first two computations. For the period October 1, 1967 to September 30, 1968 emerqency calls totaled 1523. For the last computation all calls during the year were included.

Figure 2 shows the density of calls throughout the county. Each number in the figure is the number of emergency calls received

* A call was considered to be an emergency if both siren and lights were used by the ambulance. 


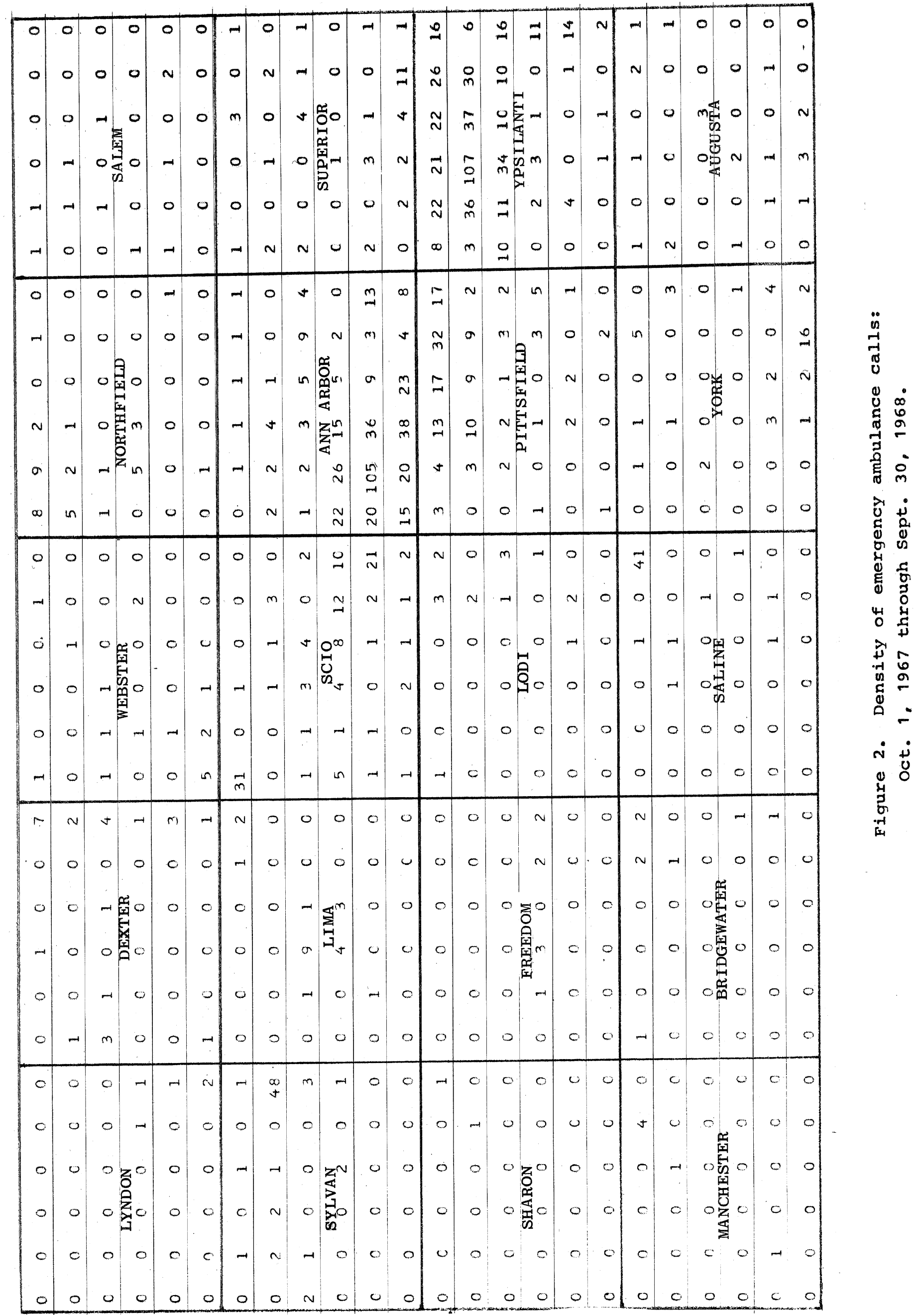




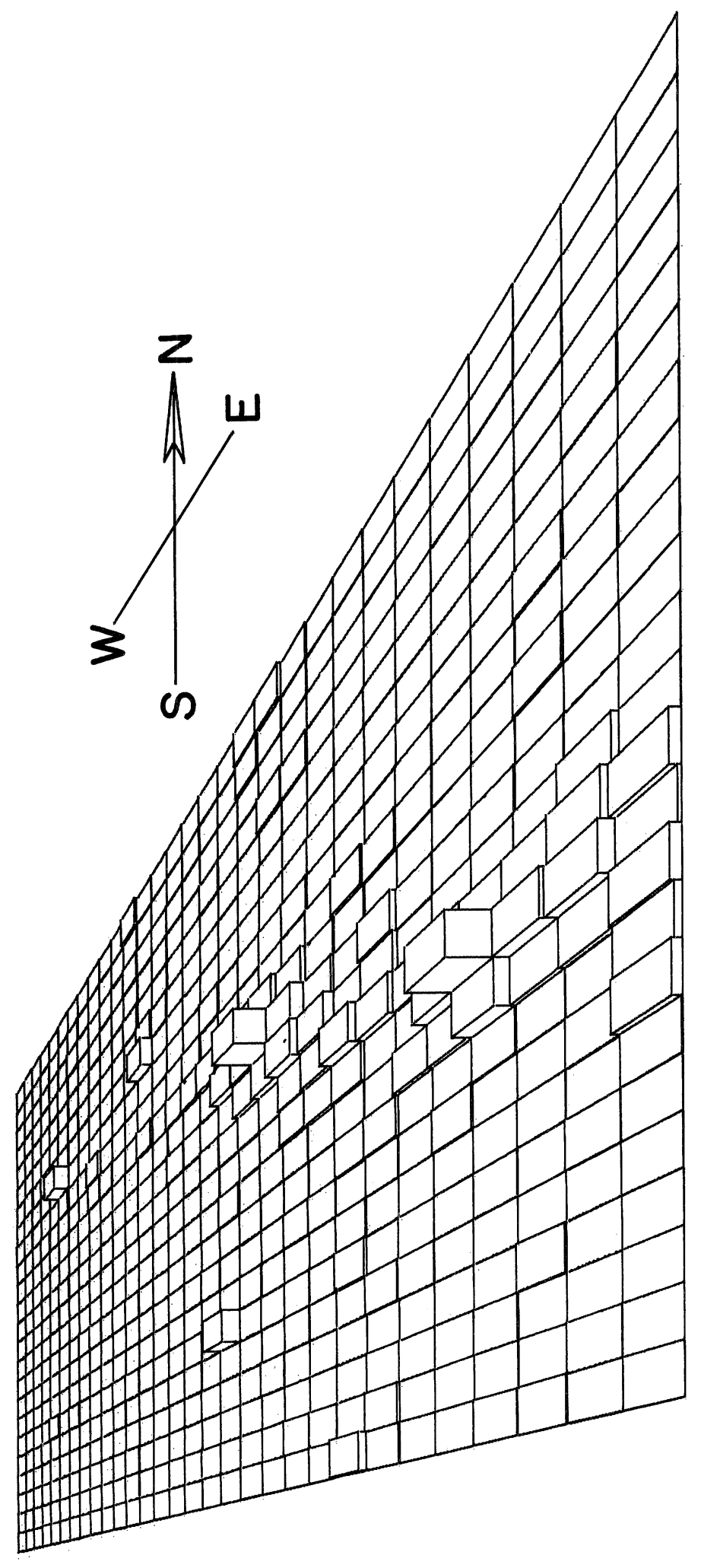

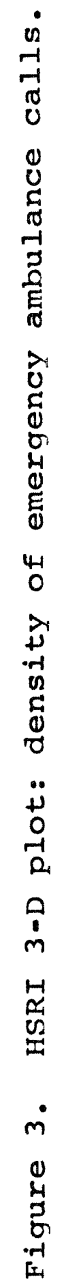


in the one-mile square indicated (compare with figure 1). As expected, there are high peaks in the major cities of the county and very few calls from the remote rural areas. While one can see some evidence of calls originating along the major expressways, this effect is certainly minimal. Fiqure 3 provides a perspective view of this density; the density pattern is viewed from the eastern direction.

The velocity coefficients were determined by selecting a sample of 273 cases, determining typical routes from county maps, and doing a least square fit of the data. The resultant velocities are shown in table $I$.

TABLE I

Average Ambulance Speed by Road Type

$\begin{array}{lc}\text { Type of Road } & \text { Average Speed } \\ \text { Expressway } & 73.2 \mathrm{mph} \\ \text { Other paved highway } & 58.1 \mathrm{mph} \\ \text { City streets } & 25.6 \mathrm{mph} \\ \text { Unpaved county roads } & 29.6 \mathrm{mph}\end{array}$

To estimate the predictive capability of this choice a different set of 142 cases was used, and the predicted and measured times were compared. The average error in this was $10^{-4}$ minute. A similar test run was performed on the original 273-case sample, and an average error of 4.2 seconds was obtained. The probability of $K$ ambulances being in service when a call is received is computed using equation $(A-5)$ and is shown in table II. From this it can be seen that the assumption that all $N$ ambulances are not in service when a call is received is valid for $N>4$. 
TABLE II

Solutions to Equation (A-5) for Washtenaw County

$\begin{array}{ll}\frac{K}{0} & \frac{p(K)}{0.67031} \\ 1 & 0.26815 \\ 2 & 0.05362 \\ 3 & 0.00715 \\ 4 & 0.00071 \\ 5 & 0.00005\end{array}$




\section{Chapter 3 \\ Results}

In order to provide a check on the validity of the entire model it was used to compute the average response for the ambulance system as it presently operates. This could not be done exactly, however, because a slightly variable relocation scheme is currently employed and the model assumes a fixed relocation scheme. What was done was to assume an average relocation scheme for present operation. The result was a predicted response time of 8.81 minutes. The measured average response time for emergency calls over a year's operation was 8.94 minutes.

The measured response time may itself be considered a random variable dependent upon the calls used in the sample. Using the standard deviation of the sample's sum together with its mean gives a better idea of the accuracy of the model. The standard deviation was estimated to be 0.15 minutes. Thus, it was seen that the model is a reasonable approximation of this system.

Table III shows the results of the unconstrained optimization runs for varying number of ambulances. The coordinates given are the $x, y$ coordinates of the one-mile squares in which the ambulances would be located.

TABLE III

Solutions to Unconstrained Problem

Number of Ambulances

Ambulance Location

Average

Response Time

$1 \quad(23,9)$

$2 \quad(19,14),(27,11)$

$3(9,17),(20,14),(27,11)$

$9.48 \mathrm{~min}$

$4(9,17),(20,14),(27,11),(23,9)$

$8.64 \mathrm{~min}$

5

$(6,17),(13,18),(20,14),(27,11),(23,9)$

$8.03 \mathrm{~min}$

6

$(6,17),(13,18),(20,14),(27,11),(18,6),(22,13)$

$7.52 \mathrm{~min}$ 
It should be pointed out that the times obtained in these runs will be approximated if the ambulances are placed at the representative points for each of the one-mile squares. Location of any ambulance at some other point in the square would result in a slightly different predicted response time. By looking at the response time for placing the vehicle at representative points in neighboring squares one can interpolate to estimate the response time for the location within a square.

It can be seen that for $\mathrm{N}=5$ (which is the number of ambulances presently in use) an improvement of about $10 \%$ over present operation could be obtained by employing a different location scheme. The major differences in location involve moving some of the ambulances closer to the point of highest density of calls, and moving some of the outlying vehicles to points that would provide them with easy entry to the portions of the cross-country highway network they are likely to use. By purchasing a sixth ambulance an improvement of about an additional half minute could be obtained.

In order to determine how the average response times to individual locations varied throughout the county the optimal locations were used with the driving time model and an array of driving times to each of the one-mile squares was computed. This was done for $N=4,5,6$. The results are shown in figures 4,5 , and 6. In which the times are given in tenths of a minute and the ambulance locations are circled. In addition to aiving information on how the response times vary, these results provide insiaht into which ambulance should be dispatched to which location. By looking at the ridges of peak response times between ambulance locations, one can divide the county into the regions to be covered by each vehicle.

It can be seen from figures 4,5 , and 6 that the response time to some of the remote corners of the county is nearly 34 minutes. Even though the population density in these areas is low, the maintenance of some minimum level of service may be desired. To try to reduce these long response times the constrained optimization procedure was used. A $T_{\max }$ of 20 minutes was chosen and it was decided that $r$ should be four; with less than four vehicles available, 


\begin{tabular}{|c|c|c|c|c|c|}
\hline 220 & $200 \quad 206 \quad 232 \quad 186 \quad 197$ & $\begin{array}{llllll}198 & 190 & 179 & 190 & 172 & 168\end{array}$ & $\begin{array}{llllll}205 & 164 & 182 & 215 & 227 & 197\end{array}$ & $\begin{array}{llllll}163 & 165 & 176 & 215 & 246 & 235\end{array}$ & $174 \quad 174 \quad 192 \quad 221 \quad 241 \quad 241$ \\
\hline & $\begin{array}{lllll}184 & 186 & 212 & 179 & 185\end{array}$ & $\begin{array}{llllll}196 & 179 & 158 & 178 & 187 & 164\end{array}$ & $\begin{array}{llllll}193 & 154 & 181 & 191 & 205 & 183\end{array}$ & $\begin{array}{llllll}175 & 152 & 189 & 204 & 225 & 214\end{array}$ & $\begin{array}{lll}81 & 188 & 221\end{array}$ \\
\hline 206 & 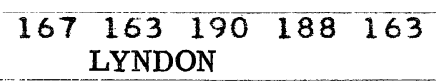 & 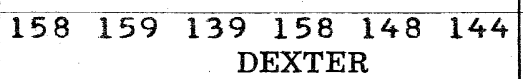 & 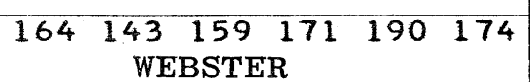 & $\begin{array}{c}9172191191 \quad 185 \\
\text { NORTHFIELD }\end{array}$ & $\begin{array}{rrrrrr}152 & 152 & 176 & 176 & 212 & 222 \\
\text { SALEM } & & & \end{array}$ \\
\hline 204 & $202 \quad 163 \quad 162 \quad 171 \quad 146$ & $\begin{array}{llllll}160 & 140 & 120 & 139 & 140 & 140\end{array}$ & $\begin{array}{llllll}148 & 136 & 168 & 169 & 162 & 151\end{array}$ & $\begin{array}{llllll}137 & 131 & 150 & 171 & 171 & 164\end{array}$ & $\begin{array}{llllll}136 & 168 & 167 & 167 & 222 & 218\end{array}$ \\
\hline & $\begin{array}{lllll}179 & 162 & 141 & 160 & 135\end{array}$ & \begin{tabular}{llllll|}
140 & 119 & 99 & 118 & 137 & 125
\end{tabular} & $\begin{array}{lllllll}144 & 128 & 162 & 173 & 181 & 194\end{array}$ & $9 \quad 156 \quad 155$ & $\begin{array}{llll}9 & 161 & 188 & 202\end{array}$ \\
\hline 165 & $\begin{array}{lllll}156 & 143 & 132 & 120 & 123\end{array}$ & $81 \quad 98 \quad 117 \quad 121$ & $\begin{array}{llllll}124 & 118 & 145 & 150 & 172 & 175\end{array}$ & $\begin{array}{llllll}155 & 119 & 139 & 177 & 147 & 135\end{array}$ & $\begin{array}{llllll}146 & 153 & 163 & 168 & 201 & 200\end{array}$ \\
\hline & $\begin{array}{lllll}151 & 163 & 157 & 126 & 108\end{array}$ & $\begin{array}{llllll}100 & 79 & 60 & 80 & 99 & 117\end{array}$ & $\begin{array}{llllll}102 & 122 & 122 & 138 & 153 & 155\end{array}$ & $\begin{array}{lllll}0 & 116 & 156 & 142 & 142\end{array}$ & $1171 \quad 183$ \\
\hline 135 & $121 \quad 126 \quad 131 \quad 120 \quad 100$ & 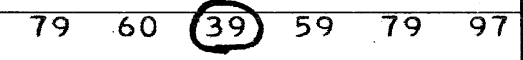 & $\begin{array}{llllll}107 & 116 & 135 & 136 & 136 & 134\end{array}$ & $97.136 \quad 113 \quad 126$ & $\begin{array}{llllll}136 & 143 & 145 & 154 & 149 & 162\end{array}$ \\
\hline & $\begin{array}{l}118 \begin{array}{lll}108106 & 109 & 77 \\
\text { SYLVAN }\end{array} \\
\end{array}$ & $\begin{array}{lllll}56 & 55 & 65 & 82 & 108 \\
\text { LIMA }\end{array}$ & $\begin{array}{ccccc}06 & 107 & 125123 & 132 & 114 \\
\text { SCIO }\end{array}$ & $\begin{array}{l}6 \quad 96116 \quad 104111 \\
\text { ANN ARBOR }\end{array}$ & $\begin{array}{cccccc}125 & 151 & 135 & 148 & 149 & 162 \\
\text { SUPERIOR } & & \end{array}$ \\
\hline 132 & $\begin{array}{lllll}126 & 108 & 92 & 80 & 77\end{array}$ & $\begin{array}{lllll}60 & 70 & 77 & 75 & 84\end{array}$ & $98 \quad 108 \quad 111 \quad 113$ & $55 \quad 75 \quad 96$ & $23 \quad 154 \quad 154$ \\
\hline 8 & $116 \quad 122 \quad 122$ & $\begin{array}{lllll}87 & 87 & 115 & 107\end{array}$ & $\begin{array}{llll}7 & 145 & 132 & 114\end{array}$ & 55 & $105122 \quad 111$ \\
\hline 147 & $\begin{array}{lllll}154 & 146 & 146 & 102 & 112\end{array}$ & $\begin{array}{llllll}133 & 115 & 120 & 126 & 130 & 109\end{array}$ & $25 \quad 135 \quad 125 \quad 123 \quad 101$ & 89 & $95 \quad 115 \quad 103$ \\
\hline 207 & $\begin{array}{lllll}185 & 151 & 141 & 123 & 115\end{array}$ & $\begin{array}{llllll}130 & 135 & 135 & 155 & 161 & 143\end{array}$ & $\begin{array}{llllll}125 & 135 & 125 & 113 & 102 & 92\end{array}$ & $96 \quad 116 \quad 93$ & 95103 \\
\hline 247 & \begin{tabular}{lllll|}
196 & 172 & 147 & 132 & 130
\end{tabular} & $\begin{array}{llllll}152 & 157 & 161 & 178 & 187 & 136\end{array}$ & $\begin{array}{llllll}153 & 174 & 162 & 138 & 115 & 107\end{array}$ & 93106 & 87 \\
\hline 250 & 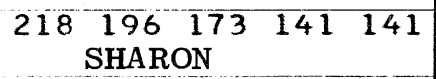 & 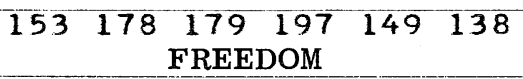 & $\begin{array}{cccccc}164 & 183 & 142 & 129 & 118 & 105 \\
\text { LODI }\end{array}$ & $\begin{array}{ccccc}117 & 116 & 97 & 89 & 69 \\
& \text { PITTSFIELD }\end{array}$ & $\begin{array}{l}7454 \quad 55 \\
\text { YPSILANTI }\end{array}$ \\
\hline 252 & $\begin{array}{lllll}228 & 218 & 201 & 183 & 151\end{array}$ & $\begin{array}{llllll}194 & 216 & 197 & 182 & 172 & 162\end{array}$ & $\begin{array}{llllll}172 & 152 & 141 & 129 & 118 & 130\end{array}$ & $\begin{array}{llll}125 & 107 & 92 & 72\end{array}$ & 95 \\
\hline 234 & $\begin{array}{lllll}213 & 213 & 204 & 183 & 182\end{array}$ & $\begin{array}{llllll}218 & 224 & 218 & 214 & 191 & 191\end{array}$ & $\begin{array}{llllll}199 & 203 & 180 & 161 & 137 & 126\end{array}$ & $138 \quad 102$ & $95 \quad 115 \quad 104$ \\
\hline 239 & $239245 \quad 223 \quad 193 \quad 208$ & $222 \quad 255 \quad 238 \quad 257.227 \quad 206$ & $209 \quad 210 \quad 192 \quad 165 \quad 143 \quad 120$ & 71100 & $\begin{array}{llllll}111 & 122 & 106 & 124 & 135 & 111\end{array}$ \\
\hline 274 & $\begin{array}{lllll}261 & 247 & 239 & 207 & 228\end{array}$ & $252 \quad 237 \quad 228 \quad 206 \quad 194 \quad 180$ & $\begin{array}{llllll}186 & 174 & 160 & 150 & 139 & 116\end{array}$ & $\begin{array}{llll}131 & 125 & 117 & 99\end{array}$ & $\begin{array}{llllll}105 & 123 & 121 & 140 & 140 & 130\end{array}$ \\
\hline 273 & $\begin{array}{lllll}253 & 252 & 242 & 230 & 235\end{array}$ & $235 \quad 230 \quad 230 \quad 219 \quad 225 \quad 208$ & $\begin{array}{llllll}219 & 206 & 168 & 153 & 153 & 138\end{array}$ & $\begin{array}{llll}139 & 120 & 113 & 94\end{array}$ & \begin{tabular}{llllll|}
104 & 121 & 115 & 123 & 148 & 136
\end{tabular} \\
\hline 281 & 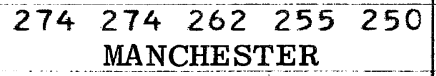 & $\begin{array}{c}260 \quad 260271 \quad 271 \quad 245 \quad 212 \\
\text { BRIDGEWATER }\end{array}$ & $\begin{array}{ccccc}196 & 183 \quad 170 \quad 156 & 159 & 161 \\
\text { SALINE } & & & \\
\end{array}$ & $\begin{array}{rr}175 & 143 \quad 149 \quad 105 \\
\text { YORK }\end{array}$ & $\begin{array}{cccccc}130 & 146 & 144 & 147 & 163 & 157 \\
& & \\
\text { AUGUSTA } & & & \end{array}$ \\
\hline 306 & $269269285275 \quad 260$ & $273 \quad 271262 \quad 247 \quad 237 \quad 212$ & $\begin{array}{llllll}181 & 184 & 207 & 194 & 162 & 177\end{array}$ & $\begin{array}{llllll}187 & 160 & 147 & 121 & 110 & 134\end{array}$ & $\begin{array}{llll}166 & 170 & 186 & 186\end{array}$ \\
\hline 295 & $\begin{array}{lllll}331 & 326 & 318 & 296 & 271\end{array}$ & $\begin{array}{llllll}277 & 283 & 272 & 251 & 228 & 198\end{array}$ & $\begin{array}{llllll}211 & 206 & 209 & 184 & 162 & 174\end{array}$ & $\begin{array}{llllll}169 & 152 & 138 & 146 & 120 & 131\end{array}$ & $\begin{array}{llllll}145 & 147 & 155 & 178 & 178 & 180\end{array}$ \\
\hline 339 & $\begin{array}{llllll}325 & 319 & 298 & 291 & 284\end{array}$ & $282 \quad 262 \quad 269 \quad 226 \quad 214 \quad 225$ & $\begin{array}{llllll}49 & 224 & 218 & 188 & 184 & 184 \\
\end{array}$ & $\begin{array}{llllll}167 & 159 & 168 & 153 & 153 & 131\end{array}$ & $\begin{array}{llllll}161 & 161 & 182 & 180 & 201 & 212\end{array}$ \\
\hline
\end{tabular}

Figure 4. Average time from receipt of call to arrival at scene: unconstrained optimal solution for four ambulances in washtenaw County. (Times are given in tenths of a minute.) 


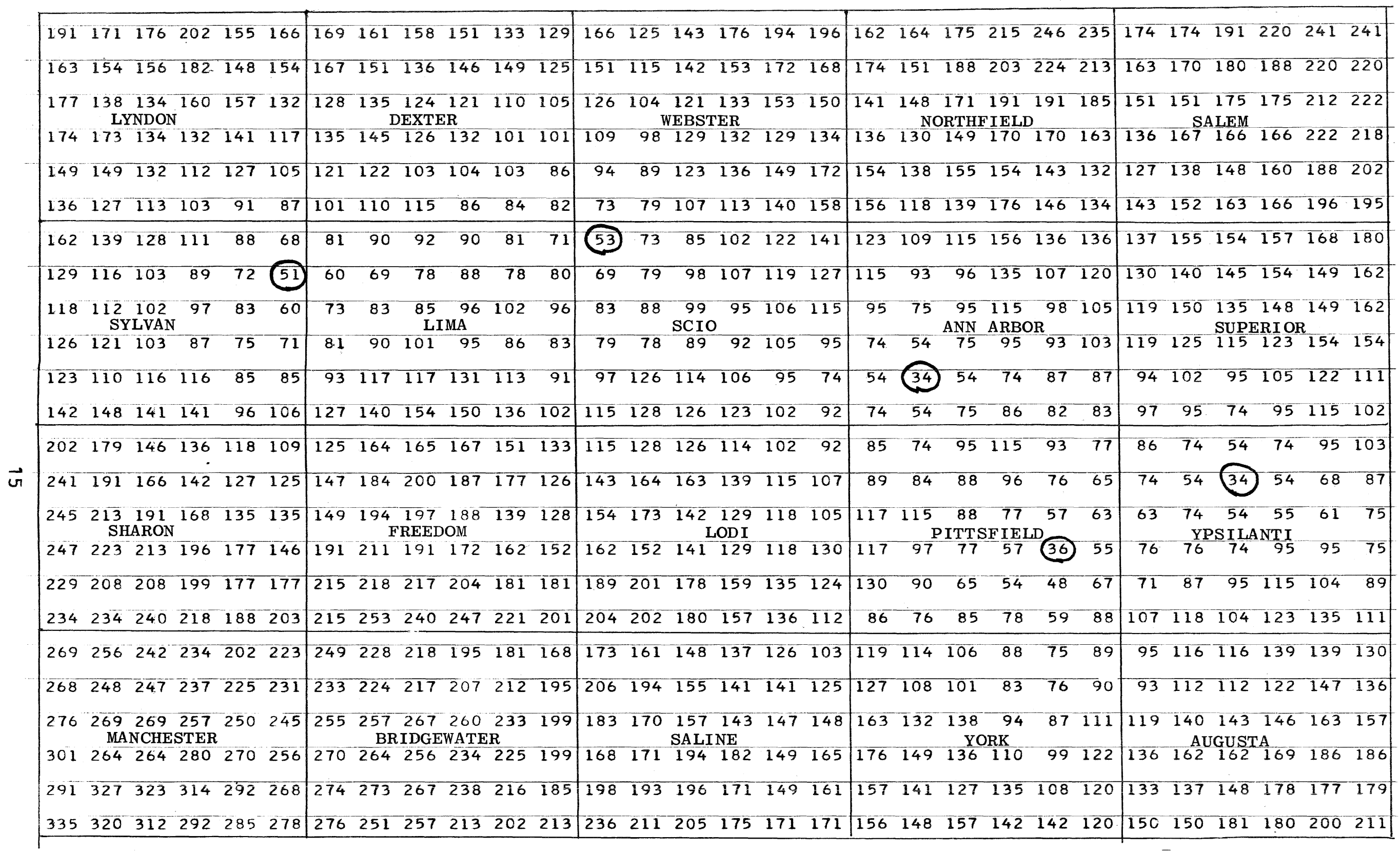

Figure 5. Average time from receipt of call to arrival at scene:

unconstrained optimal solution for five ambulances in washtenaw County.

(Times are given in tenths of a minute.) 


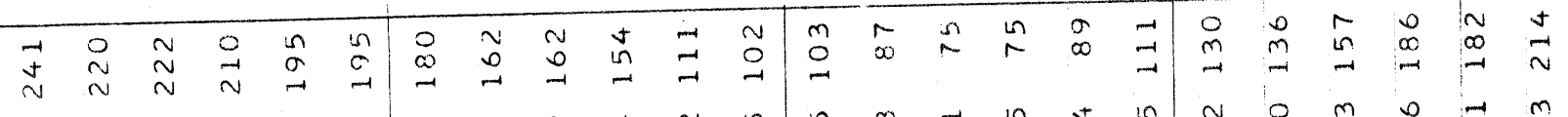

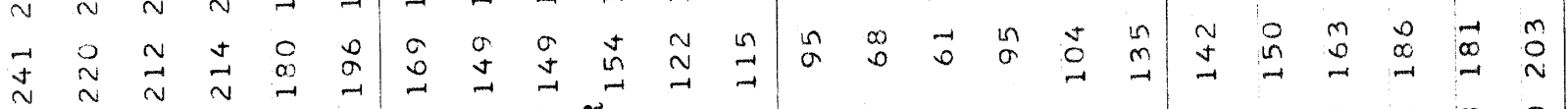

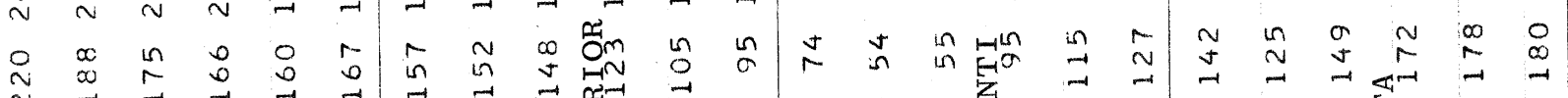

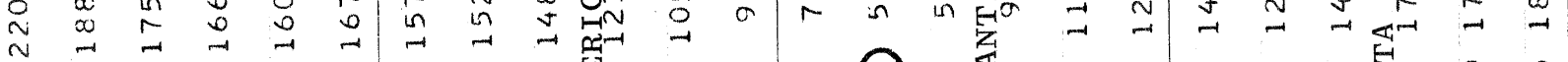

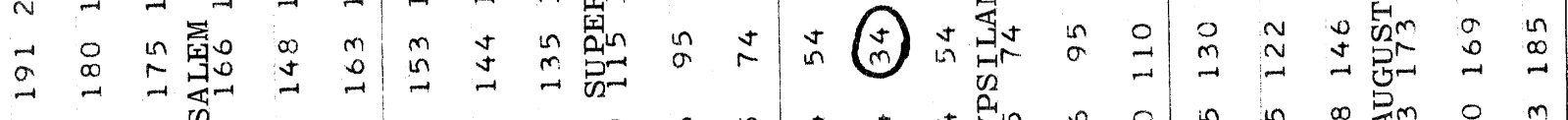

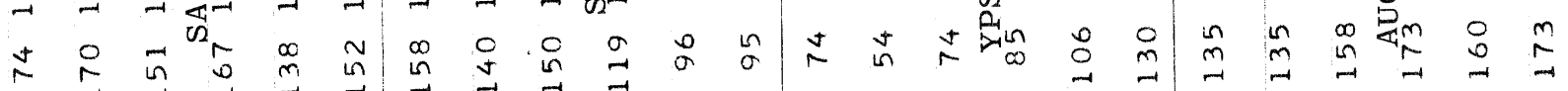

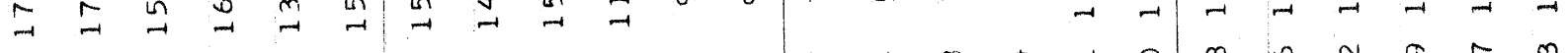

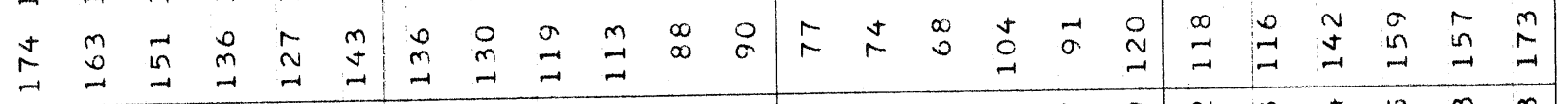

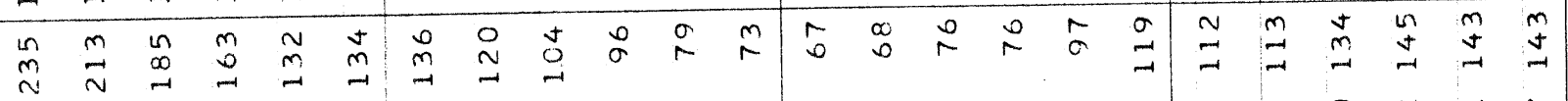

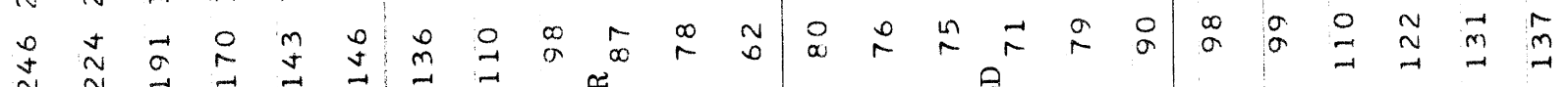

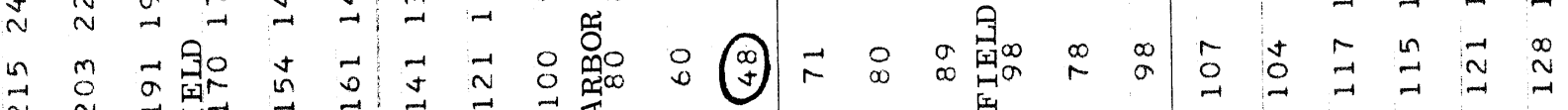

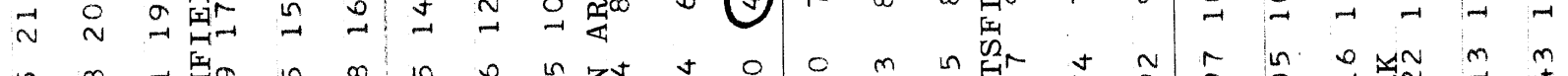

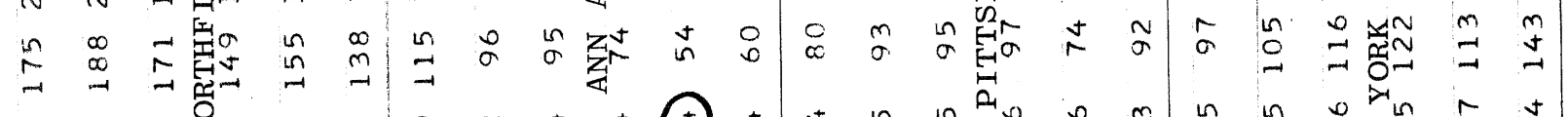

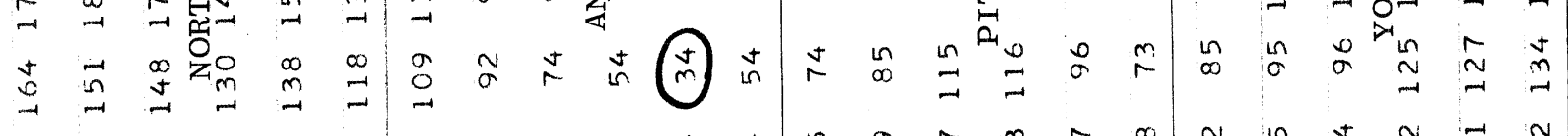

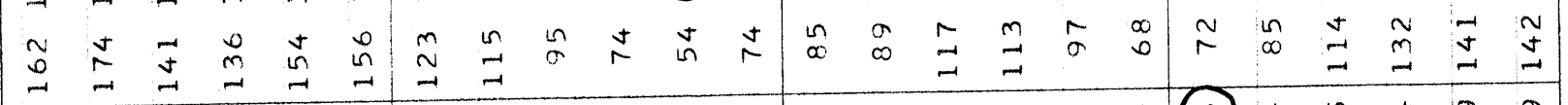

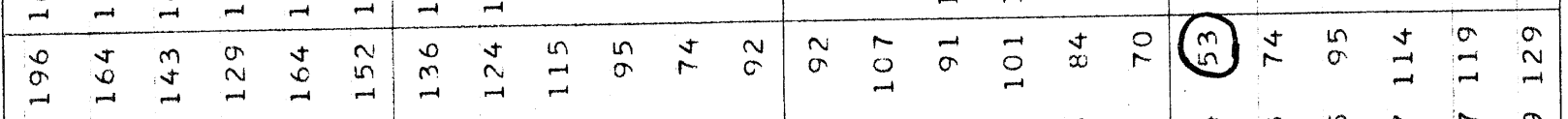

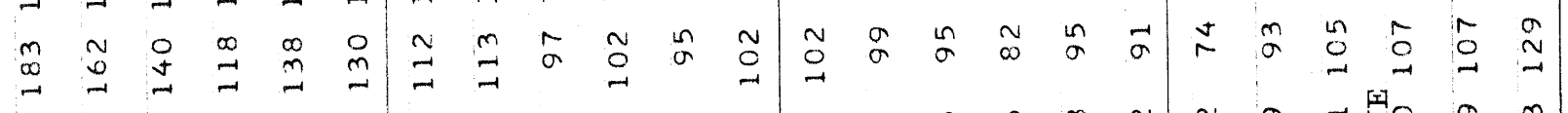

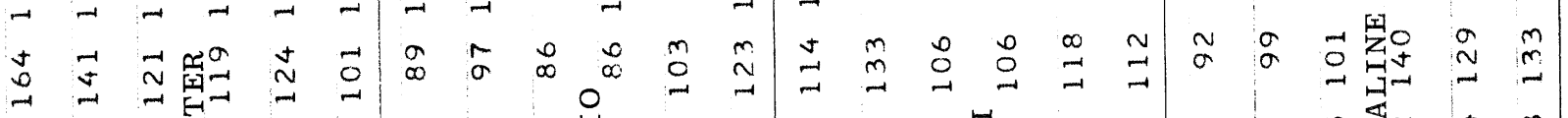

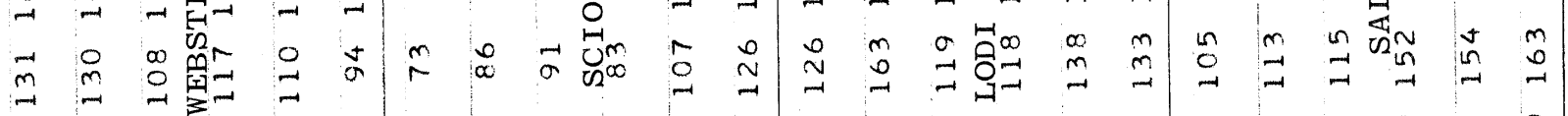

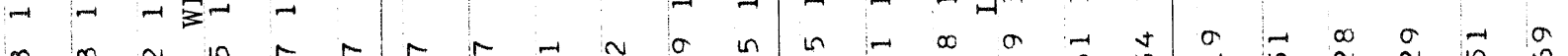

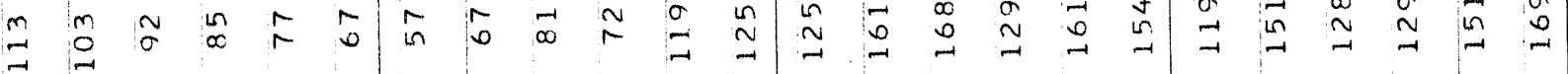

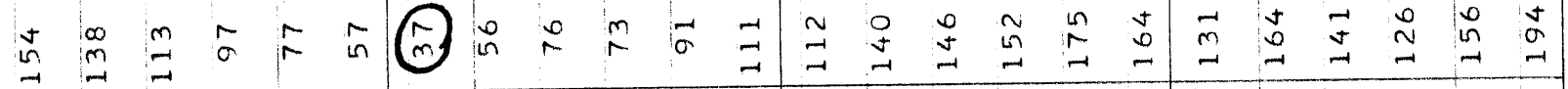

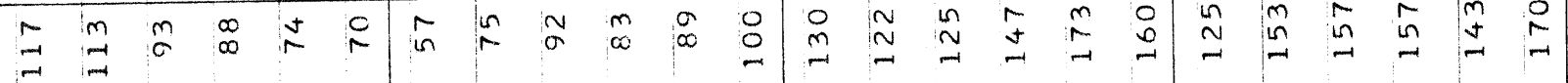

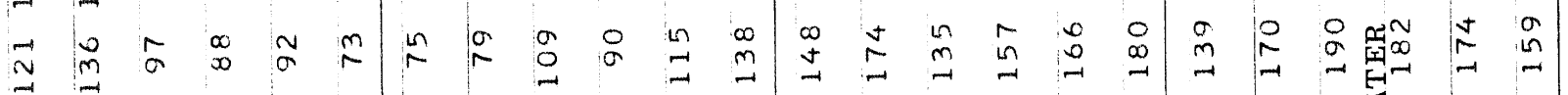

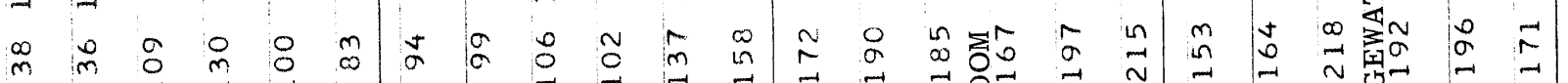

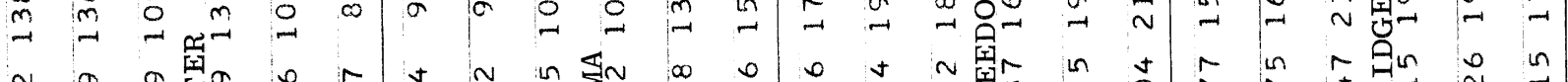

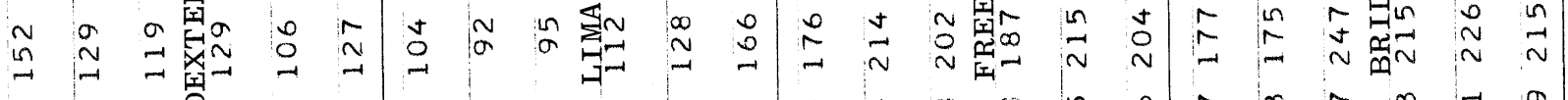

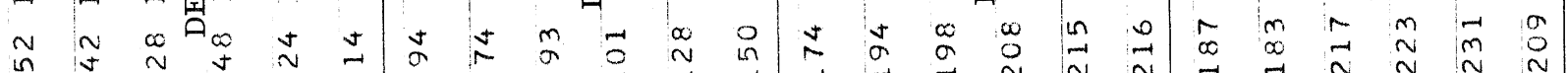

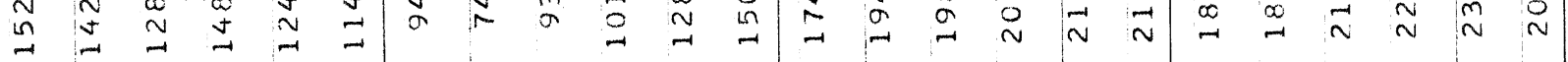

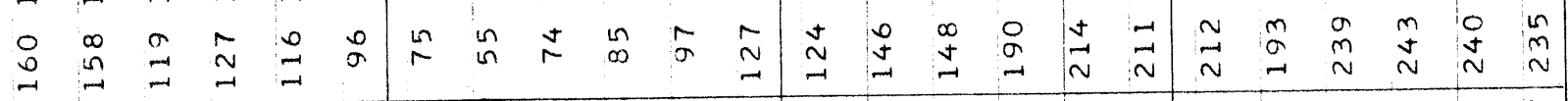

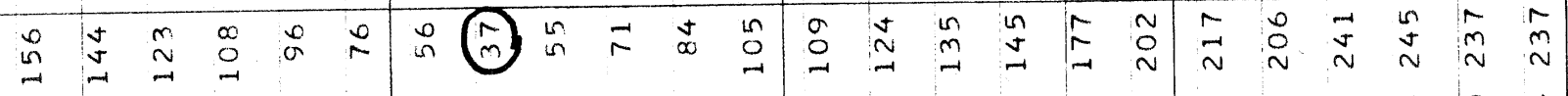

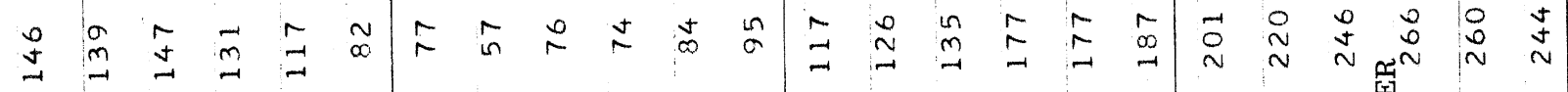

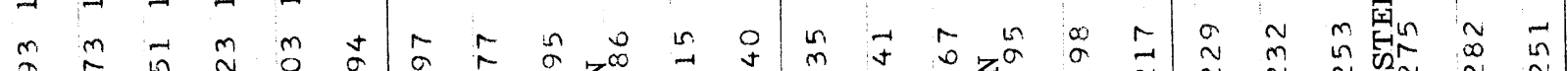

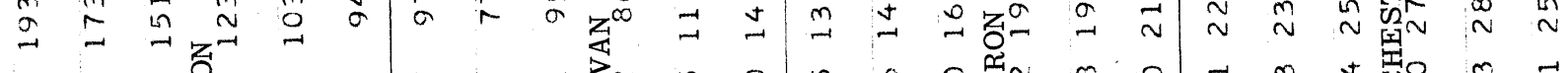

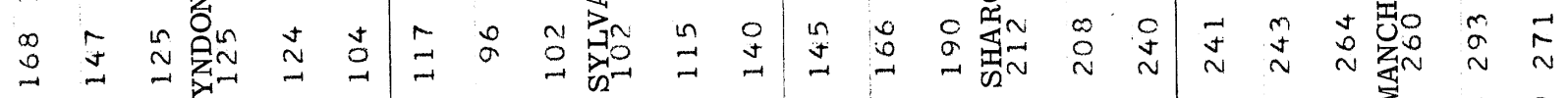

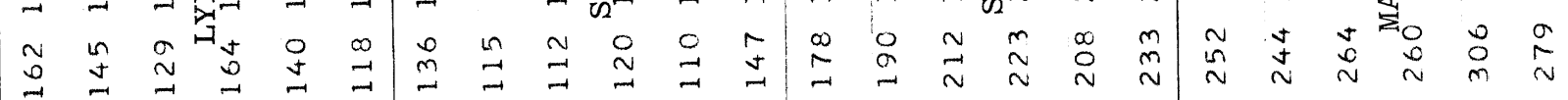

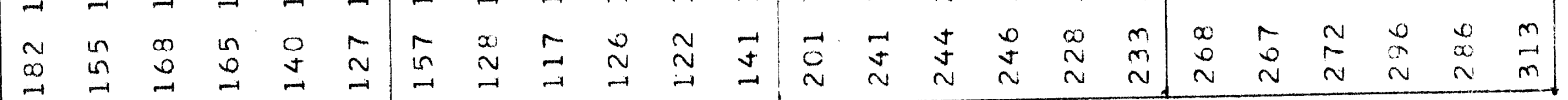


it is not possible to provide reasonable service for the areas of high density and rapid service for the remote areas of the county. The results of this study are summarized in table IV, and figures 7,8 , and 9 show how the individual response times changed.

TABLE IV

Solutions to Constrained Problem

Number of Ambulances Ambulance Locations

Average Response

\section{Ambulances}

1
2 $\quad(23,9)$

$2 \quad(19,14),(27,11)$

$3 \quad(9,17),(20,14),(27,11)$

$4(7,5),(9,17),(23,9),(20,16)$

$9.97 \mathrm{~min}$

$5 \quad(7,5),(9,17),(23,9),(20,14),(27,12)$

$9.01 \mathrm{~min}$

6

$(7,5),(9,17),(23,17),(20,14),(23,9),(27,11)$

$8.24 \mathrm{~min}$

Response times previously longer than 30 minutes were reduced to approximately 19 minutes. Only in a few locations was the constraint violated, and then only by a small amount; this was deemed acceptable. The main changes involved taking one ambulance away from a higher density area and placing it near Manchester, in the southwestern corner of the county (see fig. 1), and moving some of the vehicles covering Ann Arbor and Ypsilanti slightly north to provide more rapid response to the northeastern portion of the county.

The overall average response time, of course, increased with the incorporation of this constraint. However, it can be seen that if properly distributed, five ambulances could provide nearly the present average level of service and still furnish adequate coverage for the remote parts of the county. With an additional vehicle, remote service could be provided and overall performance improved. 




Figure 7. Average time from receipt of call to arrival at scene: const ained optimal solution for four ambulances in washtenaw County.

(Times are given in tenths of a minute.) 


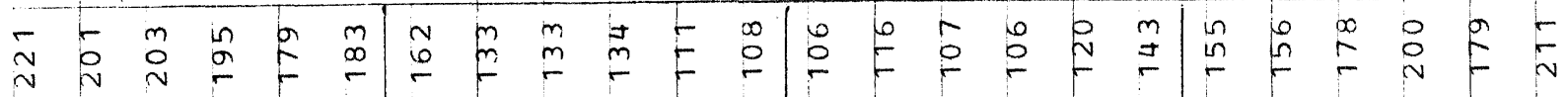

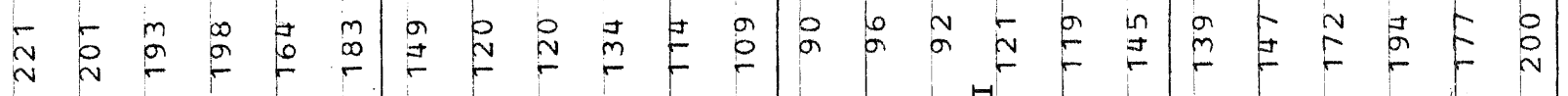
㘄

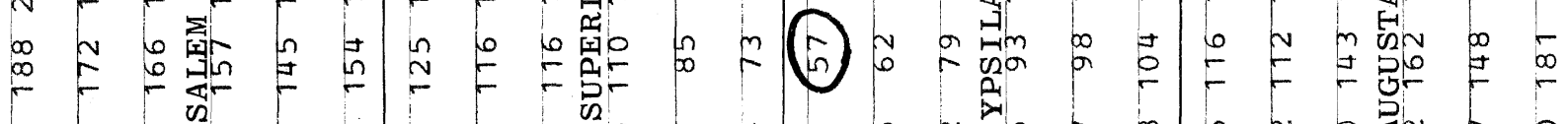

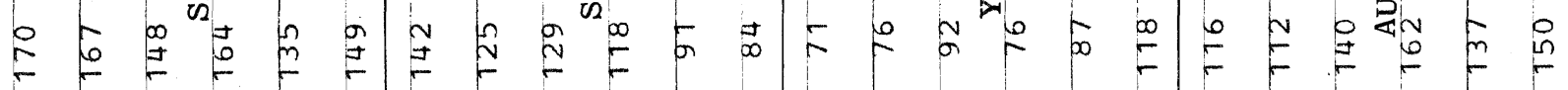

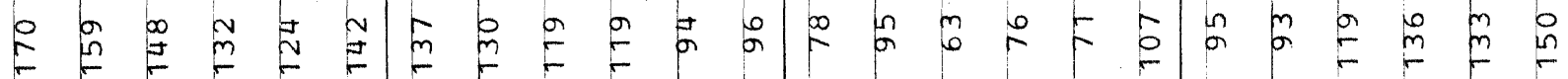

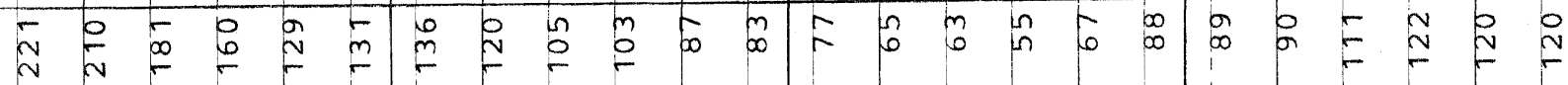

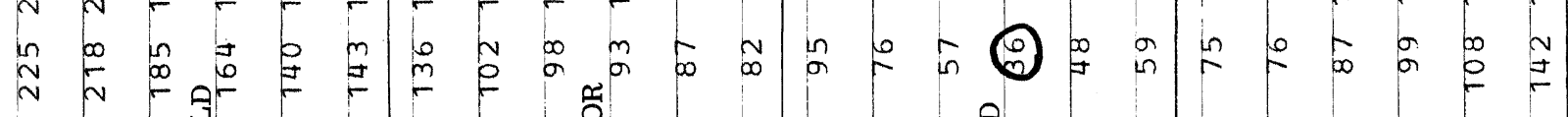

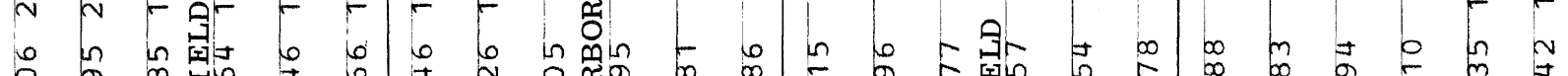

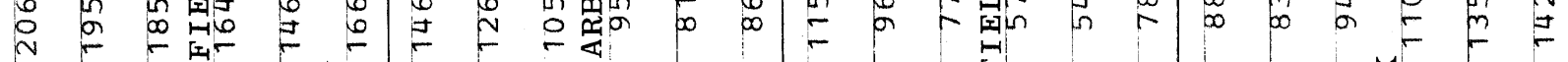

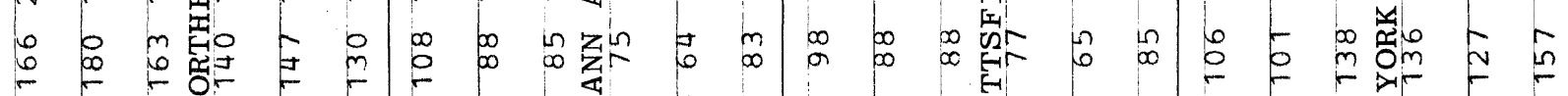

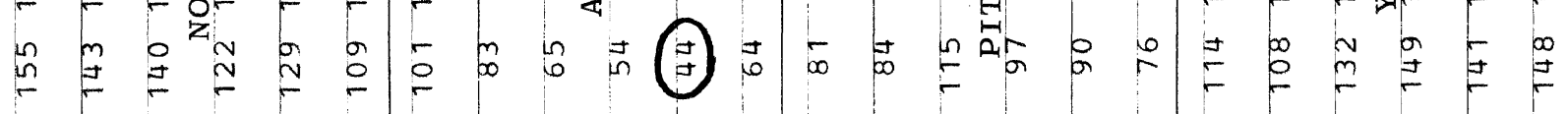
苟

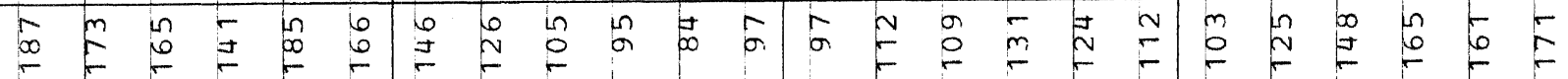
党 i)

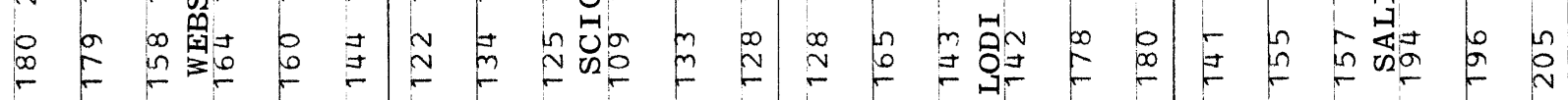

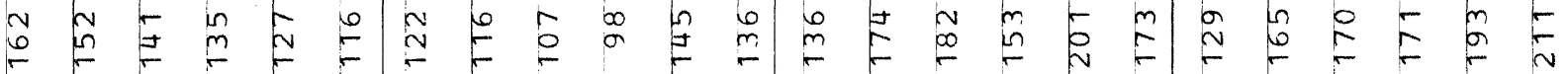

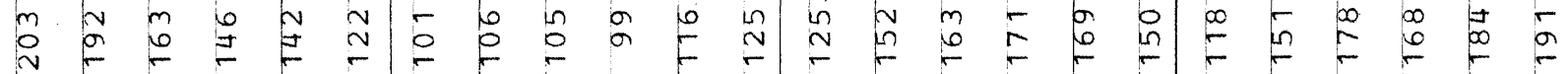

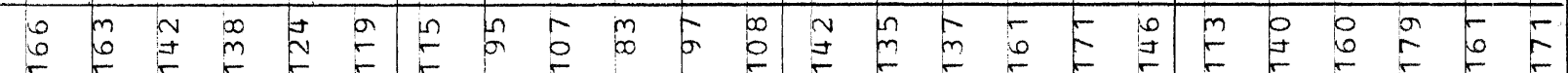

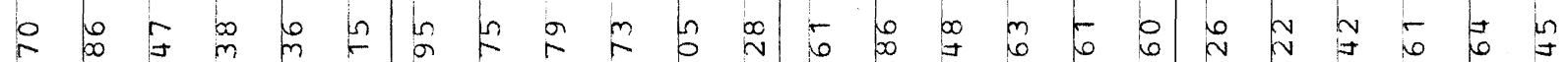

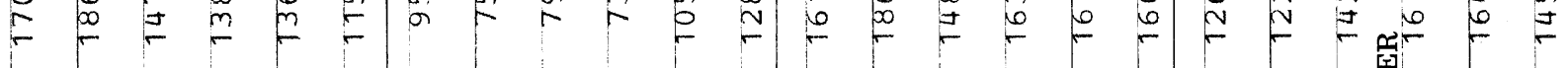

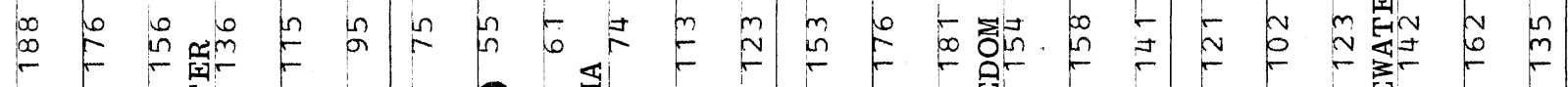

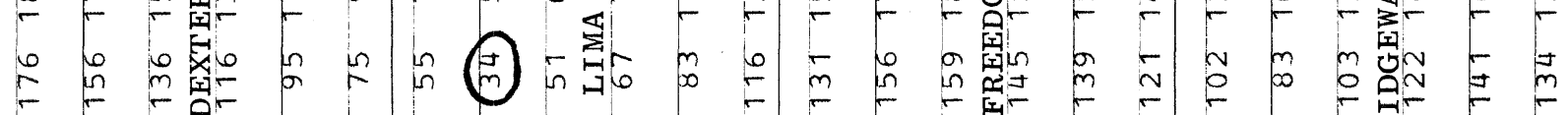

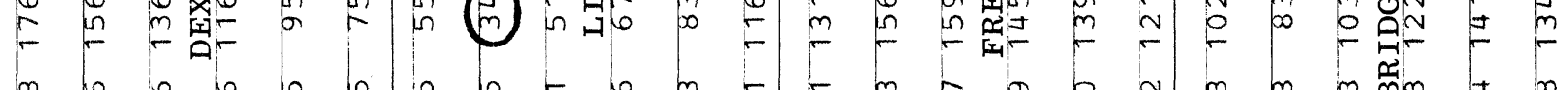

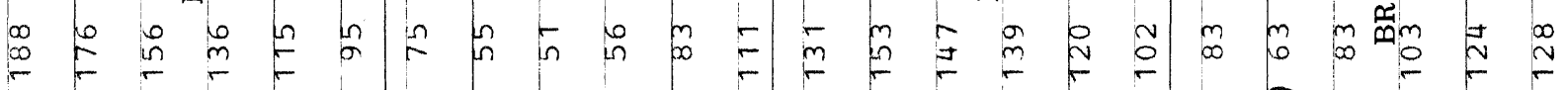

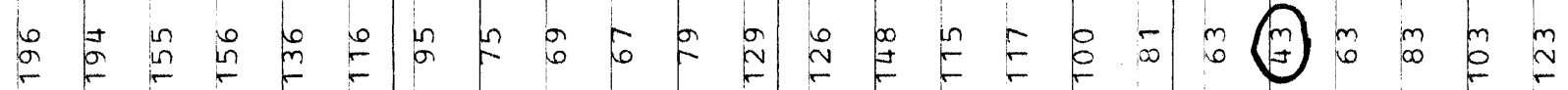

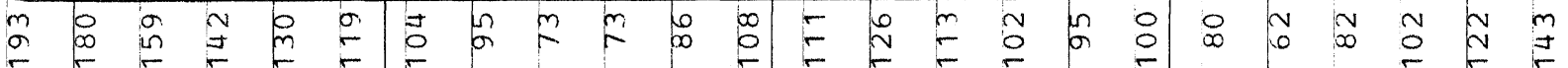

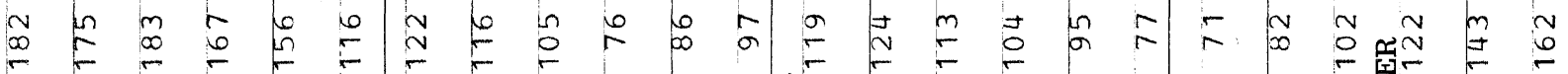

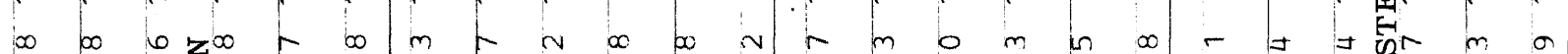

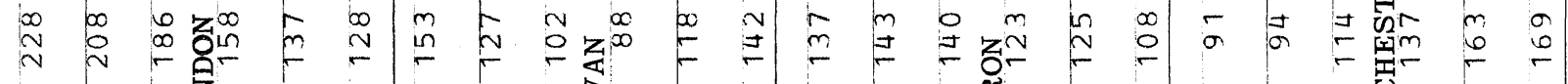
N $\mathfrak{O}^{\infty}$ a

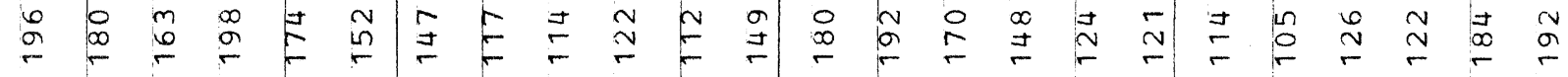

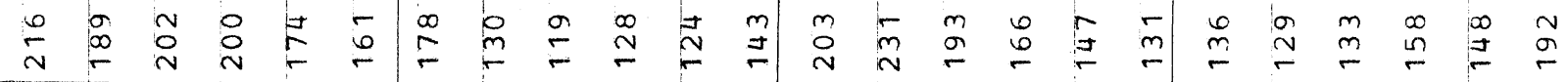




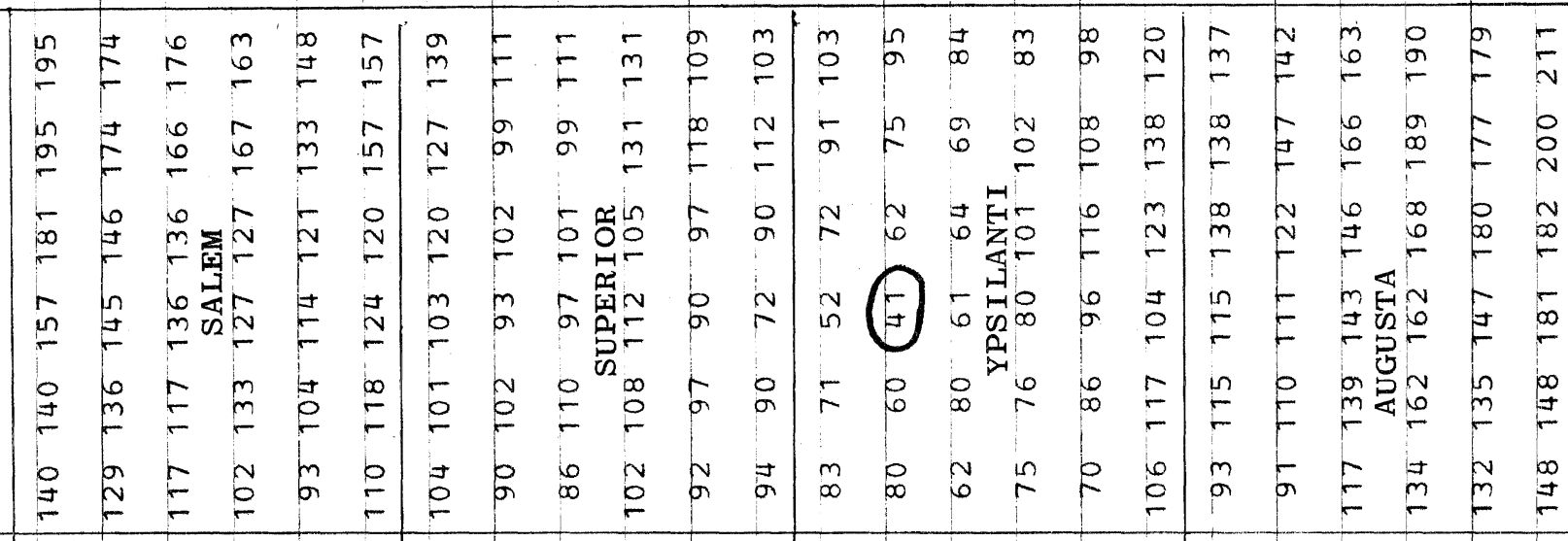

岁

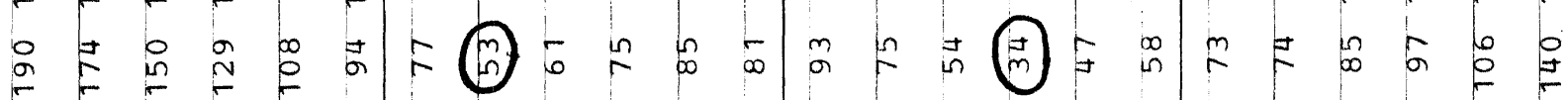

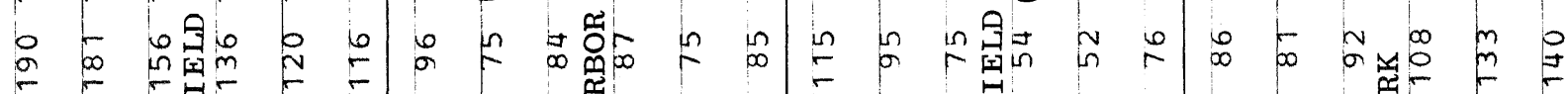

- 6 b t

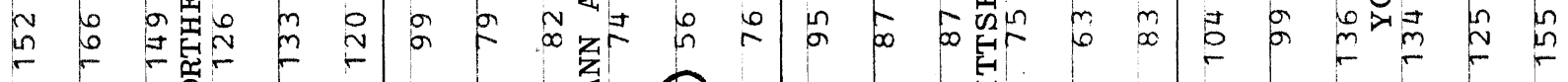

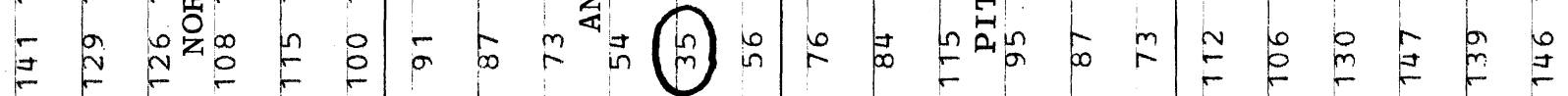

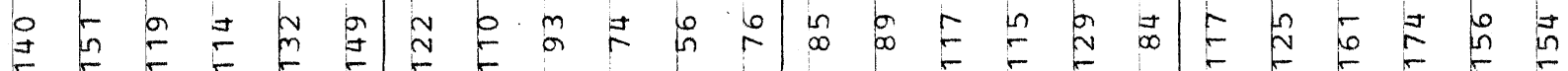

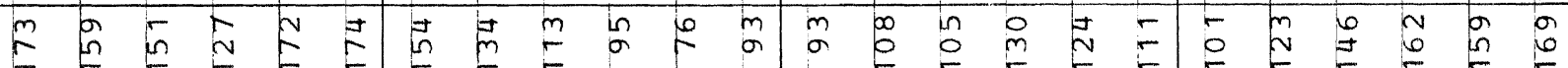

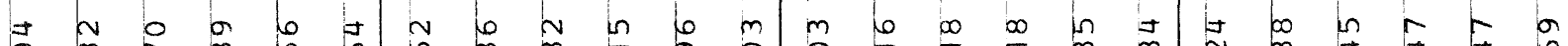

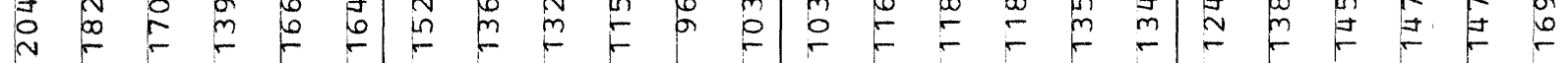

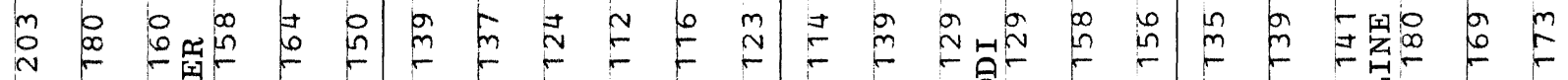

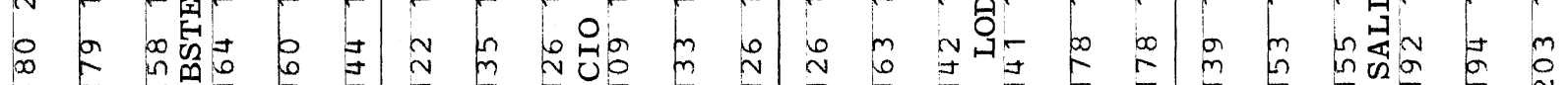

DEF

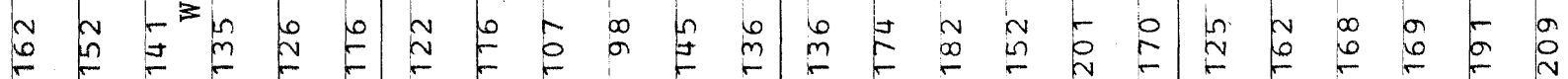

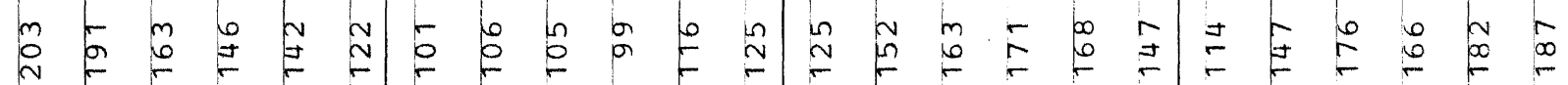

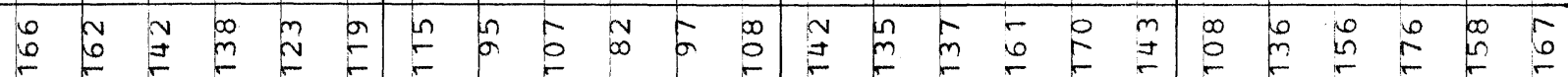

$\therefore$ b

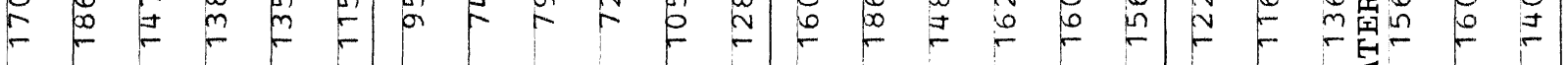

央

E

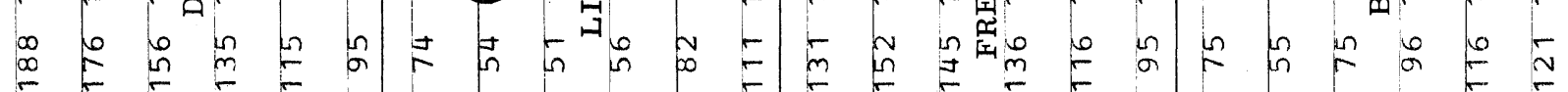

$\begin{array}{ll}0 & \dot{1} \\ 0 & \\ 0 & 5 \\ 0 & 5 \\ 0 & 0 \\ 0 & 0\end{array}$

$\underset{\pi}{\pi} \underset{\pi}{3}$

-1

$\rightarrow-5$

然

용

$\begin{array}{lll}0 & 0 & 0 \\ 7 & 0 & 0\end{array}$

ช

出 哥

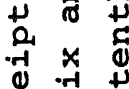

0 o

4 म

ह

$\rightarrow$ o

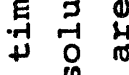

苟

出

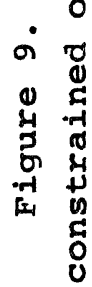

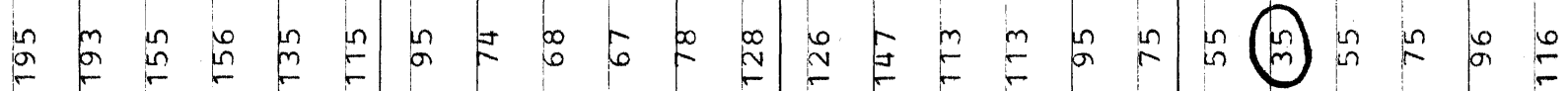

مू

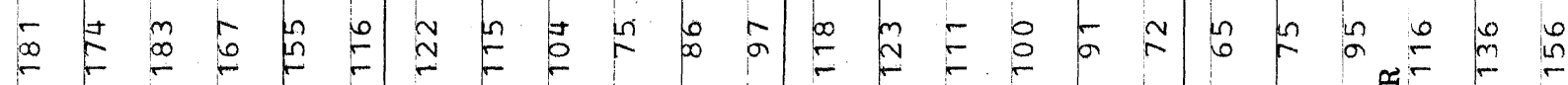

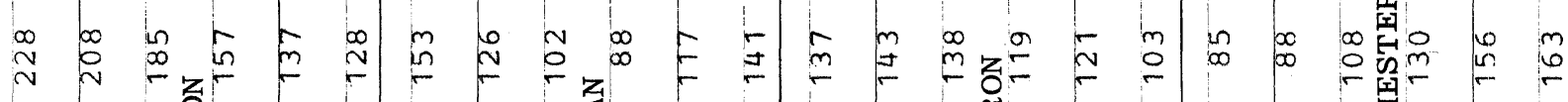

完

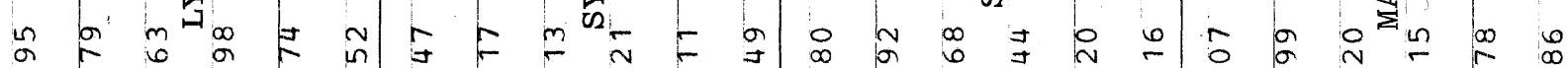

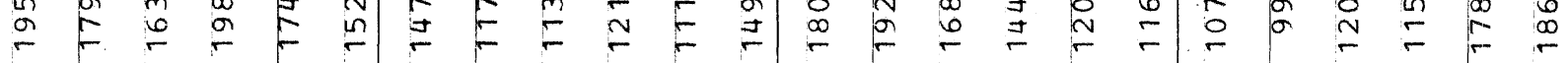

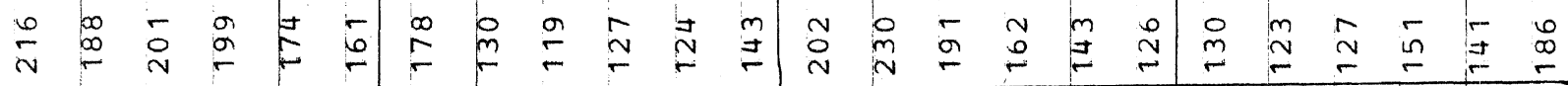


This report has considered the application of modeling and simple optimization techniques to the problem of determining station locations for ambulances in a semi-rural environment. A statistical model for the average response time to emergency calls was developed, and a new model for the driving time between any two points in the county introduced. These were seen to work very well in modeling the behavior of the system. The major disadvantage of the approach is the amount of data that must be determined from maps. Relatively inexpensive student labor was used and this was not considered a problem.

The second feature of this study was the use of a simple optimization algorithm. This removed human participation in the selection of locations by one step: Instead of seeking a solution through trial and error using a simulation of the system, the operator merely selected different starting points for the optimization program so that different local minima were found. At some expense in computer time, this too could have been programmed on the computer. The computer time required for small numbers of ambulances was quite reasonable, being less than 80 seconds for $\mathrm{N}=2$. However, the time required increased rapidly with $\mathrm{N}$. For $N=6$ nearly 11 minutes were required. Fortunately, solutions were not needed for $\mathrm{N} \geq 6$ and the total computation cost was reasonable.* The computation times were somewhat greater for the constrained case. As a result of this study and the existence of today's highspeed digital computers it is reasonable to consider the use of optimization algorithms for problems of this type.

This work was developed both to study the basic ideas involved and to apply them to ambulance operation in Washtenaw County, Michigan. The model and optimization procedure worked well for both the constrained and unconstrained cases. Examination of the resulting station locations, in terms of the county map, has shown that they are intuitively quite reasonable. In addition

*Approximately $\$ 400$ was used for the final optimization runs. About $\$ 1700$ additional was used for program development and data reduction. 
to providing useful information on where to station ambulances, the study has provided insight on what the county would gain by purchasing a new ambulance. Implementation of these results has not yet taken place, but will be under consideration in the near future. 


\section{References}

1. Harris, Britton. "Some Problems in the Theory of IntroUrban Location," Penn Jersey Transportation Study. September 30, 1962.

2. Isard, Walter. Location and Space-Economy. MIT Press, 1956.

3. Stolper, Wolfgang. The Economics of Location. Yale University Press, 1954

4. Savas, E.S. "Simulation and Cost-Effectiveness Analysis of New York's Emergency Ambulance Service," Office of the Mayor Report. New York City, March 10, 1968

5. Gordon, Geoffrey, and Kenneth Zelin. "A Simulation Study of Emergency Ambulance Service in New York City," IBM New York Scientific Center Report No. 320-2935. March, 1968 
Appendix A

Response Time

In this appendix an expression is developed for the expected value of the response time, which is defined as the time interval between the time a call is received and the time an ambulance arrives at the scene. It is assumed that when a call is received the nearest ambulance (in the sense of driving time) is dispatched. It is further assumed that if there are $\mathrm{N}$ ambulances assigned to provide service to the county of which $K$ are in service, the remaining $\mathrm{N}-\mathrm{K}$ are optimally located. That is, every time an ambulance goes into service, the remaining vehicles are instantaneously relocated in an optimal manner. Since the driving times for relocation are small relative to the average time between calls the assumption of instantaneous relocation, which greatly simplified the calculation, is reasonable.

From the above it is seen that one needs to determine not only the locations of $\mathrm{N}$ ambulances, but also the locations assuming $1,2, \ldots$ or $N-1$ ambulances are available. Thus, define $x_{j}, j=1, \ldots, N$ to be the set containing the $j$ station locations to be used if only $j$ ambulances are available. For convenience let $x_{N}=\left\{x_{i}\right\}_{1}^{N}$ denote the collection of all of these sets.

Let the driving time between any two points $z=\left(z_{1}, z_{2}\right)$ and $y=\left(y_{1}, y_{2}\right)$ be denoted by $\rho(z, y, \phi)$ where $\phi$ is a vector of all random variables which affect the driving time, e.g. weather condition, traffic condition, and time of day. Given that a call is received from a location $y$ and that $k$ ambulances are in service, the response time to that call will then be given by

$$
\rho_{2}\left(x_{N}, y, K, \phi\right)=\min _{z \in x_{N}-K} \rho_{I}(z, y, \phi)
$$


To get the average response time we simply take the expected value of $\rho_{2}\left(x_{N}, y, K, \phi\right)$ with respect to the paramaters $y, K$, and $\phi$. Denoting the average response time by $\bar{T}_{r}$ we obtain

$\overline{\mathrm{T}}_{r}=\int_{-\infty}^{\infty} \int_{-\infty}^{\infty} \int_{-\infty}^{\infty} \rho_{2}\left(x_{N}, y, K, \phi\right) f(y, K, \phi) d \phi d K d y$

where $\int d y$ and $\int d \phi$ denote the appropriate multiple integrals and $f(y, K, \phi)$ is the joint probability density function. It has been tacitly assumed that no more than $\mathrm{N}-1$ ambulances are in service when a call is received (i.e., there is always an available ambulance).

To achieve some simplification of this, several assumptions will be made. First, the county (see fig.1) which is 30 miles by 24 miles, is divided into squares one mile on a side. All calls within a one-mile square will be considered to come from a single representative point within that square and all distances from that square will be measured relative to that point. Next, it will be assumed that the variables $y, k$, and $\phi$ are statistically independent. Then, noting that $K$ takes only integer values between 0 and $N-1$, equation $(A-2)$ can be written

$$
\overline{\mathrm{T}}_{\mathrm{r}}=\sum_{K=0}^{\mathrm{N}=1} \sum_{1}^{30} \sum_{2}^{24} \bar{p}_{2}\left(x_{N}, y, K\right) p(K) p_{1}\left(y_{1}, y_{2}\right)
$$

where $\bar{\rho}_{2}\left(x_{N}, y, K\right)$ is the expected value of $\rho_{2}\left(x_{N}, y, K, \phi\right)$ w.r.t. $\phi$, $p(K)$ is the probability that $K$ ambulances are in service, and $p_{1}\left(y_{1}, y_{2}\right)$ is the probability of a call occurring in the square with coordinates $\left(y_{1}, y_{2}\right)$. 
In this form, the problem of determining the location vector in the set $X_{N}$ may be decoupled by writing equation $(A-3)$ as

$$
\begin{aligned}
& \bar{T}_{Y}=\sum_{y_{1}=1}^{30} \sum_{y_{2}=1}^{24} \bar{\rho}_{2}\left(x_{N}, y, 0\right) p(0) p_{2}\left(y_{2}, y_{2}\right) \\
& \sum_{1}^{30} \sum_{2}^{24} \sum_{k=1}^{N-1} \bar{p}_{2}\left(x_{K}, y, k\right) p(k) p_{1}\left(y_{2}, y_{2}\right)
\end{aligned}
$$

From equation $(A-1)$ it is seen that the term on the left involves only the location set $x_{N}$, while the term on the right involves $x_{1}, \ldots, x_{N-1}$ but not $x_{N}$. Thus, one may successively solve for $x, x_{2}, \ldots, x_{N}$ using at each stage the left term in equation $(A-4)$ To get $p(K)$, let there be 0 calls in a year and let the average length of service of an ambulance be $\bar{T}_{\mathbf{s}}$. Given that a call occurs at time $t, p(K)$ may be approximated by the probability that exactly $K$ calls occur during the previous $\bar{T}_{s}$ minutes. Since a call either does or does not fall within this time interval, binomial probabilities may be used, and

$p(K)=\left(\begin{array}{c}Q-1 \\ K\end{array}\right) \sigma^{K}(1-\sigma)^{Q-K-1}$

where $\sigma=\bar{T}_{s} / 1 \mathrm{yr}$. Table II(see $\mathrm{Ch}$. 2) shows a few values of $p(K)$ for Washtenaw County. It can be seen that the assumption that not all $\mathrm{N}$ ambulances are in service when a call is received is valid for $N \geq 4$. 
Although the average response time is a significant measure of the ambulance system performance, it may also be desired that no response be longer than some predetermined maximum, $T_{m}$. In an absolute sense, this cannot be guaranteed. However, one can include a constraint which would require that the average response time to any point in the county be less than $T_{m}$ if at least $r$ ambulances are available at the time a call is received. This latter condition on the number of ambulances available is necessary because if the number is too low, there may be no set of locations from which one can reach any point within $\mathrm{T}_{\mathrm{m}}$ minutes. This constraint is incorporated by using a penalty function and modifying the performance measure to:

$$
\begin{aligned}
& \overline{\mathrm{T}}_{\mathrm{r}}=\sum_{\mathrm{y}_{1}=1}^{30} \sum_{\mathrm{y}_{2}=1}^{24} \sum_{\mathrm{K}=0}^{\mathrm{N}-\mathrm{r}}\left\{\bar{\rho}_{2}\left(\mathrm{x}_{\mathrm{N}}, \mathrm{Y}, \mathrm{K}\right)+\frac{1}{\varepsilon} \operatorname{Pos}\left[\mathrm{T}_{\mathrm{m}}-\bar{\rho}_{2}\left(\mathrm{x}_{\mathrm{N}}, \mathrm{y}_{1}, \mathrm{~K}\right)\right]\right\} \mathrm{p}(\mathrm{K}) \mathrm{p}_{1}\left(\mathrm{y}_{1}, \mathrm{y}_{2}\right) \\
& +\quad \sum_{1}^{30} \sum_{2}^{24} \sum_{k=1}^{N-1} \sum_{k=N-1}^{-}\left(x_{N}, y, K\right) p(K) p_{2}\left(y_{1}, y_{2}\right)
\end{aligned}
$$

where

$$
\operatorname{Pos}(w)=\left\{\begin{array}{l}
w \text { if } w>0 \\
0 \text { if } w \leq 0
\end{array}\right.
$$

and $\varepsilon$ is an arbitrary small positive number. 
Appendix B

Driving Time Model

From equation $(A-1)$ it is seen that calculating the response time requires the ability to compute the point-to-point driving time between any pair of points. This can be written

$\rho_{1}(z, y, \phi)=\int_{\Gamma} \gamma(w, \phi) d w+\gamma_{0}(\phi)$

where $\gamma(w, \phi)$ is the reciprocal velocity along the path $\Gamma$, and $\gamma_{0}(\phi)$ is the delay in starting, and $\Gamma$ is the path chosen between $z$ and $\mathrm{Y}$.

As an approximation, let all roads be divided into four categories (1) limited-access expressways, (2) paved county roads, (3) city streets, and (4) unpaved county roads. Then let $\Gamma_{i}=\{z: z \varepsilon \Gamma$ and $z$ on a road of type $i\}$. In other words, $\Gamma_{i}$ is that portion of $\Gamma$ consisting of roads of type $i$. Thus $r=\Gamma_{1} U \Gamma_{2} U \Gamma_{3} U \Gamma_{4}$ and the integral in equation $(B-1)$ can be written

$\rho_{1}(z, Y, \phi)=\int_{\Gamma_{1}} \gamma(w, \phi) d w+\int_{\Gamma_{2}} \gamma(w, \phi) d w+\int_{\Gamma_{3}} \gamma(w, \phi) d w+\int_{\Gamma_{4}} \gamma(w, \phi) d w+\gamma_{0}(\phi)$ 
But, $\int_{\Gamma_{i}} \gamma(w, \phi) d w$ is simply the average inverse velocity $\gamma_{i}(\phi)$ over $\Gamma_{i}$ multiplied by the length of path $\Gamma_{i}, d_{i}$. Thus,

$$
\rho_{1}(z, y, \phi)=\gamma_{0}(\phi)+\gamma_{0}(\phi) d_{1}+\gamma_{2}(\phi) d_{2}+\gamma_{3}(\phi) d_{3}+\gamma_{4}(\phi) d_{4}
$$

$$
\begin{aligned}
& \text { Letting } \bar{\gamma}_{i}=E\left[\gamma_{i}(\phi)\right] \text { this can be written } \\
& \bar{\rho}_{1}(z, y)=\bar{\gamma}_{0}+\bar{\gamma}_{1} d_{1}+\bar{\gamma}_{2} a_{2}+\bar{\gamma}_{3} d_{3}+\bar{\gamma}_{4} d_{4}
\end{aligned}
$$

where the expectation is carried out relative to the random variables $\phi$.

In order to complete the driving time model, the path and, hence, the distances $d, \ldots, d$ must be specified. It is at this point that the key approximation in the model is made. A set of M (59 for Washtenaw County) "major", intersections were selected from the county map and an array of driving times between them computed using equation $(B-3)$. Denoting this array by $A$, the driving time from intersection $i$ to intersection $j$ then is $A(i, j)$. In this and subsequent time calculations, the distances $d_{i}$ were obtained by using typical routes determined from area maps.

For each of the one-mile square subdivisions of the county, three surrounding intersections were selected. These may be viewed as possible entry points to the cross-country travel network. This information is stored in a second array $B_{0} ; B_{0}\left(j, z_{1}, z_{2}\right)$ contains the index of the $j$-th $(j=1,2,3)$ intersection near the coordinate $\left(z_{1}, z_{2}\right)$. Similarily a third array $B_{1}$ containing the driving time from $\left(z_{1}, z_{2}\right)$ to intersection $B_{0}\left(j, z_{1}, z_{2}\right)$ may be generated. 
$B_{1}\left(j, z_{1}, z_{2}\right)$ is the driving time from $B_{0}\left(j, z_{1}, z_{2}\right)$ to $\left(z_{1}, z_{2}\right)$.

To determine an estimate of the driving time from $z=\left(z_{1}, z_{2}\right)$

to $y=\left(y_{1}, y_{2}\right)$ one can form

$$
\begin{aligned}
& \alpha(z, y)=\min \left\{B_{1}\left(i, z_{1}, z_{2}\right)+A\left[B_{0}\left(i, z_{2}, z_{2}\right), B_{0}\left(j, y_{1}, y_{2}\right)\right]+B_{1}\left(j, y_{1}, y_{2}\right)\right\} \\
& 1<i<3 \\
& 1 \overline{\leq j} \leq 3
\end{aligned}
$$

In instances where $z$ and $y$ are close it will be faster for the ambulance to take a more direct route from $z$ to $y$, which may be approximated by the sum of the coordinate distances. Since this route will generally only involve city streets or unpaved roads and since $\gamma_{3}$ and $\gamma_{4}$ do not differ widely, the inverse speed $\bar{Y}_{\text {was }}$ wapplied to all such distances. Thus a second quantity

$\beta(z, y)=\left(\left|z_{1}-y_{1}\right|+\left|z_{2}-y_{2}\right|\right) \cdot \bar{\gamma}_{4}$

is computed. Then the driving time from $z$ to $y$ is computed as

$\bar{p}_{1}(z, y)=\min [\alpha(z, y), \beta(z, y)]$ 
Finally, to obtain $\bar{\rho}_{2}\left(\mathrm{x}_{\mathrm{N}}, \mathrm{z}, \mathrm{K}\right)$ we form

$$
\bar{p}_{2}\left(x_{N}, y, K\right)=\min _{z \in x_{N-K}} \bar{p}_{1}(z, y)
$$




\section{Appendix C}

Optimization Algorithm

In order to minimize $\overline{\mathrm{T}}_{\boldsymbol{r}}$, the problem is decoupled as in equation $(A-4)$ and iteratively solved for $N=1,2, \ldots$, Hence we assume that the solutions for $x_{1}, \ldots, x_{N-1}$ are known.

The sum on the right of equation $(A-4)$ depends only on $K \geq 1$, and hence only on $x_{1}, \ldots, x_{N-1}$. Thus, this term is known and the minimization may be carried out with respect to the lefthand sum

$\mathrm{p}_{1}\left(\mathrm{x}_{\mathrm{N}}\right)=\mathrm{p}(0) \sum_{y_{1}=1}^{30} \sum_{y_{2}}^{24} \bar{p}_{2}\left(\mathrm{x}_{\mathrm{N}}, \mathrm{y}, 0\right) \mathrm{p}_{1}\left(\mathrm{y}_{1}, \mathrm{y}_{2}\right)$

in which the only variable is $x_{N}$.

To minimize $T_{i}\left(x_{N}\right)$ a discrete version of steepest descents is used. For convenience, let $x_{N}$ also denote an ordered vector of the elements of the set $x_{N}$. Beginning with an initial guess $x_{N}^{0}$, a sequence of location vectors is generated via the equation

$x_{N}^{i+1}=x_{N}^{i}+\alpha^{i} \Delta T_{1}\left(x_{N}^{i}\right)$ 
where $x_{N}^{i}$ is the $i-t h$ element in the sequence, $\Delta T_{1}\left(x_{N}^{i}\right)$ is a direction from $x_{N}^{i}$ and $\alpha^{i}$ is chosen to minimize $T_{1}\left(x_{N}^{i}+\alpha \Delta T_{1}\left(x_{N}^{i}\right)\right)$.

Due to the discretization of the county into one mile squares, several simplifications occur. First, only integer values need be considered for the entries in $x_{N}^{i}$. Thus a suitable descent direction may be found by forming the forward and backward differences $\Delta \mathrm{T}_{1}^{f}\left(\mathrm{x}_{N}^{i}\right)$ and $\Delta \mathrm{T}_{l}^{b}\left(\mathrm{x}_{N}^{i}\right)$ where $j$-th components are given by

$$
\begin{aligned}
& \Delta T_{1 j}^{f}\left(x_{N}^{i}\right)=T_{1}\left(x_{N}^{i}+e_{j}\right)-T_{1}\left(x_{N}^{i}\right) \\
& \Delta T_{1 j}^{b}\left(x_{N}^{i}\right)=T_{1}\left(x_{N}^{i}\right)-T_{1}\left(x_{N}^{i}-e_{j}\right)
\end{aligned}
$$

where the $e_{j}$ are the standard basis elements in $\mathrm{E}^{2 \mathrm{~N}}$. Then, one may choose $\Delta T_{1}\left(x_{N}\right)$ so that its $j-t h$ component is

$$
\Delta T_{i j}\left(x_{N}^{i}\right)=\left\{\begin{array}{l}
\Delta T_{1 j}^{f}\left(x_{N}^{i}\right) \text { if } 0 \leq-\Delta T_{1 j}^{f}\left(x_{N}^{i}\right) \geq T_{1 j}^{b}\left(x_{N}^{i}\right) \\
\Delta T_{1 j}^{b}\left(x_{N}^{i}\right) \text { if } 0 \leq T_{1 j}^{b}\left(x_{N}^{i}\right)>-\Delta T_{1 j}^{f}\left(x_{N}^{i}\right) \\
0 \quad \text { otherwise }
\end{array}\right.
$$


That is, each component of $\Delta T_{1}\left(x_{N}^{i}\right)$ is chosen to bring about the greatest decrease in $\mathrm{T}_{1}$.

The sequence of $\left\{\mathrm{T}_{1}\left(\mathrm{x}_{\mathrm{N}}^{\dot{i}}\right)\right\}$ generated by the above procedure will clearly be nonincreasing. Since the entries of $x_{N}$ may take on only integer values over a finite domain, there are only a finite number of possible values for $T_{1}\left(x_{N}^{i}\right)$. Hence, the iteration using equations $(C-2)$ and $(C-3)$ must eventually yield $x_{N}^{i+1}=x_{N}^{i}$. This is a natural stopping condition for the iteration. As a final check for a local minimum $T_{1}\left(x_{N}^{i}\right)$ is evaluated at all points in a neighborhood of $x_{N}^{i}$ (this is reasonable since there are only a finite number of possibilities).

The major difficulty encountered in the implementation of the problem was the existence of local minima. These occur naturally at many points in the county. For example, it is reasonable to expect a local minimum to occur at most expressway entries, for if one moves the station a short distance away from the entry point, the driver would, for many calls, simply have to drive back to the expressway entry. This problem was overcome in the usual way by restarting the procedure from a number of different points. 
